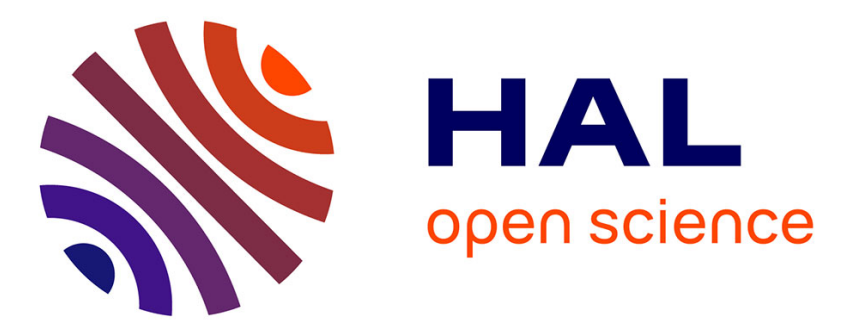

\title{
Effect of nano-silica particles on the hydration, the rheology and the strength development of a blended cement paste
}

\author{
F. Lavergne, R. Belhadi, J. Carriat, A. Ben Fraj
}

\section{- To cite this version:}

F. Lavergne, R. Belhadi, J. Carriat, A. Ben Fraj. Effect of nano-silica particles on the hydration, the rheology and the strength development of a blended cement paste. Cement and Concrete Composites, 2019, 95, pp.42 - 55. 10.1016/j.cemconcomp.2018.10.007 . hal-01900692

\section{HAL Id: hal-01900692 \\ https://hal.science/hal-01900692}

Submitted on 22 Oct 2018

HAL is a multi-disciplinary open access archive for the deposit and dissemination of scientific research documents, whether they are published or not. The documents may come from teaching and research institutions in France or abroad, or from public or private research centers.
L'archive ouverte pluridisciplinaire $\mathbf{H A L}$, est destinée au dépôt et à la diffusion de documents scientifiques de niveau recherche, publiés ou non, émanant des établissements d'enseignement et de recherche français ou étrangers, des laboratoires publics ou privés.

\section{(ㅇ)(1) $\$$}

Distributed under a Creative Commons Attribution - NonCommercial - NoDerivatives| 4.0 


\title{
Effect of nano-silica particles on the hydration, the rheology and the strength development of a blended cement paste
}

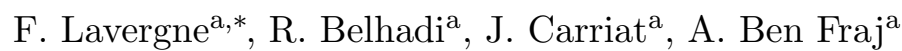 \\ ${ }^{a}$ Cerema, Equipe-projet DIMA, 110 rue de Paris, BP 214, 77487 Provins Cedex, France
}

\begin{abstract}
The aim of the present work is to evaluate the effect of nano-silica (NS) on the hydration, the rheology and the strength development of cement pastes. The advance of chemical reactions is monitored by mean of isothermal calorimetry and thermogravimetric analysis: adding nano-silica particles speeds up the hydration of the cement paste but alter its workability. Indeed, the effect of the nano-silica particles on the hydration kinetics can be modelled by accounting for its high specific surface and a flocculation model based on the DLVO theory is proposed so as to investigate the stability of nano-silica suspensions in the fresh cement paste. As a consequence, the dosage of nano-silica can be optimized to promote the early age strength. Lastly, a ternary blend incorporating fly ash can be designed so as to provide an early age strength similar to that of the cement while lowering the induced $\mathrm{CO}_{2}$ emissions.
\end{abstract}

Keywords:

nanoparticles, hydration, flocculation, strength

\section{Introduction}

Nano-silica (NS) has been successfully incorporated to cementitious blends to improve their mechanical properties [1, 2, 3, 4, 5, 6, 7,. Indeed, this material of choice combines a specific surface higher than that of silica fume and an efficient pozzolanic activity as it is made of amorphous silica, just like silica fume. It is therefore a promising addition to cementitious materials. Indeed, the improvement of performances induced by Nano-silica (NS) particles may help reducing $\mathrm{CO}_{2}$ emissions without compromising the mechanical performance and durability of modern cementitious materials, in particular by considering ternary blends [8]. Nevertheless, existing experimental evidences on the effect of NS particles can be inconclusive. For instance, the 28 day compressive strength unevenly depends on both the weight fraction of NS in the binder and its specific surface [3. For instance, to maximize the 28 days compressive strength of a cement paste of water to binder ratio $w / b=0.23$, the optimal weight fraction of NS of specific surface $200 \mathrm{~m}^{2} / \mathrm{g}$ is about $3 \%$, against $1.5 \%$ for NS of specific surface $380 \mathrm{~m}^{2} / \mathrm{g}$ due to dispersion problems [3]. On the contrary, if the water to cement ratio is 0.5 , the compressive strength increases up to $12 \%$ weight of added NS particles of specific surface $60 \mathrm{~m}^{2} / \mathrm{g}$ [1]. The compressive strength at all ages and $w / c=0.3$ or $w / c=0.5$ increases with the weight fraction of added NS of specific surface $250 \mathrm{~m}^{2} / \mathrm{g}$ up to $6 \%$ weight [5]. Depending on the water to binder ratio, the considered amount of NS, their specific surface and the amount of superplasticizer, the improvement of the 28 days compressive strength of a cement paste can be moderate (from $47 \mathrm{MPa}$ to $50 \mathrm{MPa}$ ) [5], significant (from $79 \mathrm{MPa}$ to $97 \mathrm{MPa}$ ) 2, or impressive (from $55 \mathrm{MPa}$ to $98 \mathrm{MPa}$ ) but highly variable 3 . As a result, there is a need for a deeper understanding of the effect of NS on the hydration kinetic, workability and compressive strength of a cement paste by mean of modelling [5].

Most of existing studies associate NS particles to a superplaticizer so as to recover similar rheology [1, 2, 4, 5, 9, 6. Nevertheless, the superplaticizer can interfere with the hydration kinetics. On the contrary, the present study is focused on the effect of nano-silica alone, so as to obtain clear trends and enable modelling of the hydration kinetics, which is monitored by mean of isothermal calorimetry [1, 6] and thermogravimetric analysis (TGA) [4]. For instance, the consumption of Portlandite by the pozzolanic reactions can be investigated by performing thermogravimetric analysis at different ages [5]. As an alternative, X-ray diffraction also unveils that the pozzolanic activity of NS is greater than that of silica fume [2].

\footnotetext{
${ }^{*}$ Corresponding author
}

Email address: francis.lavergne@cerema.fr (F. Lavergne)

Postprint of Cement \& Concrete Composites doi.org/10.1016/j.cemconcomp.2018.10.007 
The effect of NS particles on the rheology of fresh cement pastes has already been explored [10]: NS particles featuring a high specific surface clearly arms the workability of the cement paste. NS particles have often been introduced in combination to a variable amount of plasticizer: increasing weight fractions of NS particles are clearly correlated to higher plasticizer content to recover similar rheology [4, 9, 6. Moreover, the amount of plasticizer required to disperse the NS particles depends on the specific surface of NS [3]. The present study aims at investigating the effect of NS particles alone on the rheology of the paste. It is studied according to the DLVO theory [11, 12, where the Van der Waals attraction and the electrostatic repulsion are to be evaluated. To this end, the concentrations of ions in the pore solution of a fresh cement paste and the resulting complexation of ions on the surface of the NS particles inducing the surface charges need to be modelled [13, 14, 15, 16]. The pore solution model of Eijk and Brouwers [17] is to be adapted to account for the sulphate concentration due to gypsum.

The puzzling effect of the added NS on the compressive strength of the cement paste can be discussed in the view of the proposed evidences regarding hydration and rheology. On the one hand, the hydration is accelerated due to the specific surface of NS particles, thus explaining the impressive early strength. On the other hand, the compressive strength can be impaired by the effect of NS on the rheology of the cement paste. Finally, ternary blends incorporating both fly ash and NS particles exhibit improved early strength [7]. Therefore, a ternary blend incorporating NS particles and fly ash is designed so as to exhibit an early strength and a long term strength similar to that of a pure cement paste, but reduced $\mathrm{CO}_{2}$ emissions.

\section{Effect of nano-silica on the hydration kinetics of the cement paste}

The effect of nano-silica on the hydration kinetics of the cement paste is monitored by mean of isothermal calorimetry and thermogravimetric analysis.

\subsection{Materials, proportions and mixing procedure}

Different cement pastes featuring various amounts of NS $(1.5 \%, 3 \%$ and $5 \%$ by the weight of binder) are considered and compared with reference one ( $0 \%$ of NS). Two types of mixtures made with water-to-binder ratio 0.35 and 0.45 . The considered cement is CEM I $52.5 \mathrm{~N}$, from Calcia. Other mixes incorporating fly ash are also investigated (Tab. 1.2). The chemical and physical properties of considered materials are summarized in table 1.1. As observed, the BET surface of NS particles is ten times higher than that of silica fume $\left(20 \mathrm{~m}^{2} / \mathrm{g}\right)$, which could increase the water demand of cementitious matrix and affect its hydration kinetic. In addition, the rapid cooling of these nano-silicates warns any crystallization; NS particles are composed of amorphous silica, like silica fume, giving them a pozzolanic aspect which is difficult to be evidenced, regarding the low substitution rates. The considered white powder of NS particles is hydrophilic fumed silica, CAS number 112945-52-5, also known as pyrogenic silica, obtained by thermal flame hydrolysis [18].

Regarding $\mathrm{CO}_{2}$ emissions, the lime $\mathrm{C}$ bonded in the clinker of the considered cement represents $51 \%$ of the weight of the cement. Hence, the carbon dioxide $\overline{\mathrm{C}}$ emissions related to the calcination is about $0.4 \mathrm{t} / \mathrm{t}$ of cement. The emissions related to reach the temperature required for obtaining clinker and the grinding process depend on the origin of the energy: in France, a life cycle analysis estimated the equivalent release of $\mathrm{CO}_{2}$ to $0.866 \mathrm{t} / \mathrm{t}$ of CEM I [19]. The silica fume and the fly ash are assumed to be by-products of steel industry or electricity production, thus releasing no equivalent $\mathrm{CO}_{2}$. Lastly, the pyrogenic silica nanoparticles are produced by evaporating $\mathrm{SiCl}_{4}$ and burning it with $\mathrm{O}_{2}$ and $\mathrm{H}_{2}$ [18. This process alone emits about 0.64 ton of $\mathrm{CO}_{2}$ per ton of nano-silica. In addition, the silicon may be sourced from ferrosilicon and producing the ferrosilicon emits about 2.5 ton of $\mathrm{CO}_{2}$ per ton of nano-silica [20].

Table 1.1: The considered materials, along with some of their features.

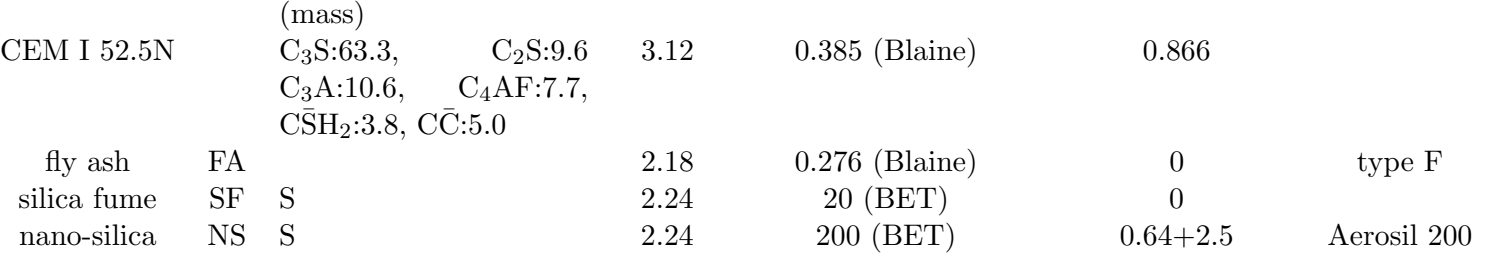


Table 1.2: Names of the binders and their weight proportions

$\begin{array}{ccccc} & \text { cement } & \text { FA } & \text { SF } & \text { NS } \\ \text { C1000 } & 100 & & & \\ \text { C985NS015 } & 98.5 & & & 1.5 \\ \text { C970NS030 } & 97 & & & 3 \\ \text { C950NS050 } & 95 & & & 5 \\ \text { C926SF074 } & 92.6 & & 7.4 & \\ \text { C811FA189 } & 81.1 & 18.9 & & \\ \text { C776FA191NS033 } & 77.6 & 19.1 & & 3.3\end{array}$

A specific protocol is applied in preparing nano-silica suspension. This preparation is performed under an extractor hood; water is firstly weighed then nano particles are added and handily mixed with water before their mixing with a mixer for $2 \mathrm{~min}$. This protocol is similar to that defined in [21, 22, in the sense that the solid nano-silica particles are introduced in the water as-is, without any alkaline additive, thus forming a gel. The mixing time is long enough for the mix to become globally homogeneous, even if the NS particles might be agglomerated at the smallest scale. The advantage of a laboratory-prepared suspension is the absence of stabilizer used in commercialized products. The high $\mathrm{pH}$ induced by such alkaline stabilizers could affect the reaction mechanism and kinetic of the cementitious matrix, particularly in presence of pozzolanic materials. The different cement pastes, detailed in table 2, are prepared in a 15L-mixer, according to the procedure detailed in figure 1.1. After mixing, prismatic molds of $4 \times 4 \times 16 \mathrm{~cm}$ and cylindrical ones of $11 \times 22 \mathrm{~cm}$ are filled with prepared pastes, and a shock [23] and vibrating [24] table are respectively used, in order to avoid pores and ensure compact mixtures. Indeed, the use of nano particles affects greatly the rheology of manufactured specimens, which made very difficult their implementation.

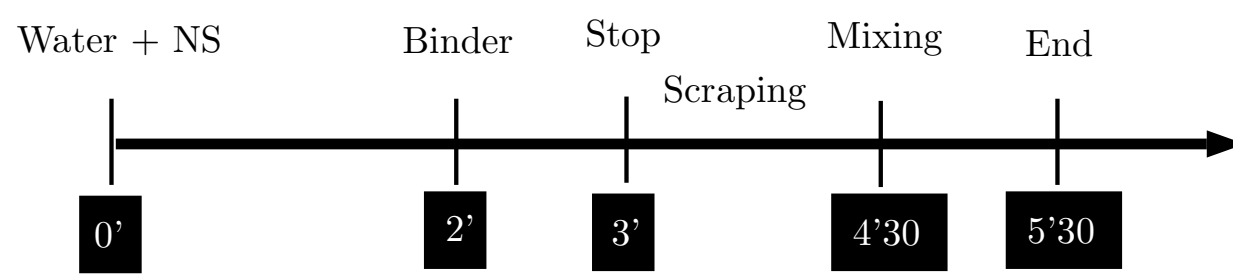

Figure 1.1: Mixing procedure

The considered additions features different specific surfaces and chemical compositions. These features must be accounted for as the hydration of the formulated cement paste is modelled.

\subsection{Modelling of cement hydration in brief}

The hydration model for blended cements proposed in 25$]$ is extended to NS particles. Asis, the model provides an estimate of the advance of the various chemical reactions occurring in the cement paste. Both the hydration reactions of the cement and the pozzolanic reactions of silica fumes and fly ashes are accounted for. In addition, the mineral additions provide additional surfaces promoting the chemical reactions: this catalytic effect, called the filler effect, partly attenuates the dilution effect, that is the replacement of the cement by less reactive materials. The filler effect could also be described as a seeding effect as nanoparticles are considered [26], involving nucleation as its physical origin. Nevertheless, the dependence to the interparticle distance also points shearing mechanisms as another plausible physical origin [27] for quartz fillers, fly ashes, slag and limestone fillers. The considered reactions are exothermic, bind water and reduce the capillary porosity, thus leading to the increase of the compressive strength of the cement paste.

NS particles are very similar to silica fume particles: both are made of amorphous silica, stemming from a rapid cooling. NS particles are therefore modelled as pozzolanic additions, just like silica fumes. Nevertheless, as NS particles feature a very high specific surface, the filler effect is likely more important than for silica fumes. Therefore, the rate $\alpha_{i}$ describing the consumption of the chemical species $i$ varies directly with the specific surface of the binder, including that of the NS particles:

$$
\dot{\alpha}_{i}(t)=\frac{w_{c} S_{c}+w_{N S} S_{N S}}{w_{c} S_{0}} g(R H, T) f\left(\alpha_{i}(t), N\right)
$$


where $S_{0}=385 \mathrm{~m}^{2} / \mathrm{kg}$ is a reference specific surface, $g(R H, T)$ and $f(N)$ are respectively functions accounting for the relative humidity $R H$, the temperature $T$ and the chemical composition $N$ at time $t$. The specific surface of the binder is a weighted sum of the Blaine specific surface of the cement $S_{c}$ and a specific surface for the NS particles $S_{N S}$, the weights being the weight fractions of the cement $w_{c}$ and NS particles $w_{N S}$. The equation above can easily be extended to ternary blend by accounting for there weight fraction and an equivalent Blaine specific surface. For instance, the equivalent specific surface for silica fumes was set to $2000 \mathrm{~m}^{2} / \mathrm{kg}$ in [25]. The experimental tests performed in the sequel are expected to provide an estimate for the equivalent Blaine specific surface for NS particles.

\subsection{Experimental results}

\subsubsection{Isothermal calorimetry}

Measuring the heat released by the chemical reactions provides a valuable insight on the advance of the chemical reactions at early age. By using isothermal microcalorimetry at a uniform temperature of $20^{\circ} \mathrm{C}$, the temperature dependence of the different reaction rates can be omitted as the results are interpreted. It is shown on figure 1.2 that cement pastes incorporating NS particles release heat more rapidly than both the reference cement paste and the cement paste incorporating silica fumes. This effect is visible at both water-to-binder ratio $w / b=0.35$ and $w / b=0.45$. Indeed, as the measurement of the heat flux starts, a large flux is observed. It could be related to initial dissolution of alite, the rapid release of alkaline ions in the solution, the dissolution of gypsum and the rapid formation of a layer of hydration products on the cement grains occurring within the first minutes after the mix [28, 29. It might also be related to a slight difference between the temperature of the freshly mixed cement paste and the temperature imposed by the calorimeter. Therefore, the cumulated released heat can be estimated by integrating the heat flux starting from the first minimum, a few minutes after the mix (Fig. 1.3).
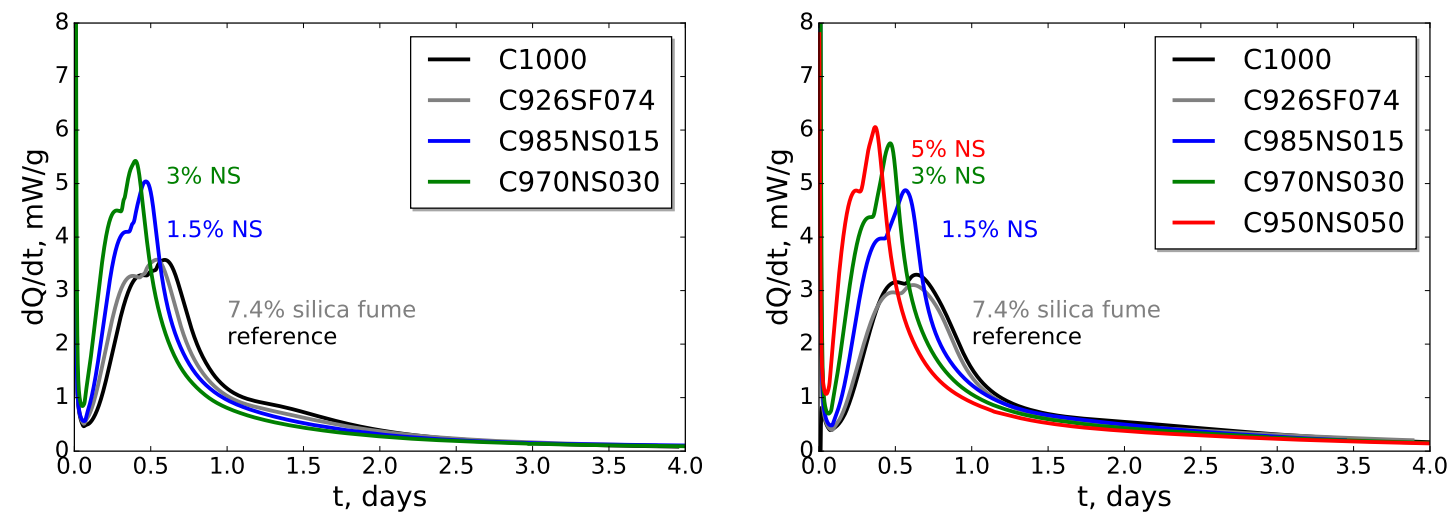

Figure 1.2: Released heat per weight of binder during isothermal calorimetry tests. $w / b=$ 0.35 (left) and $w / b=0.45$ (right).
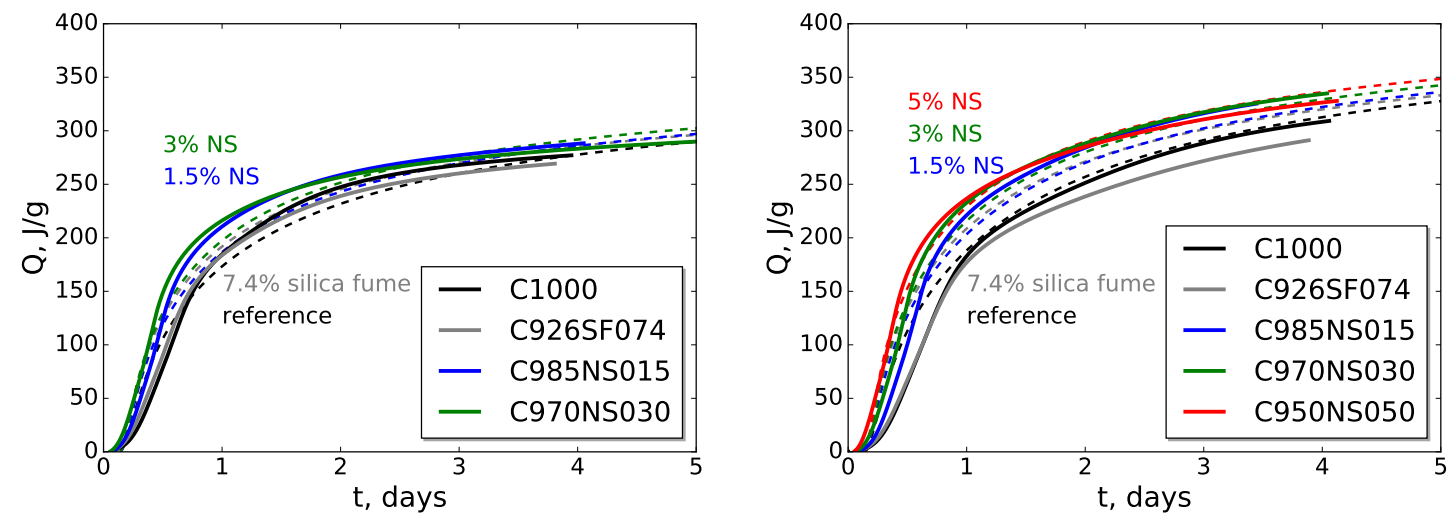

Figure 1.3: Cumulated released heat per weight of binder during isothermal calorimetry tests. $w / b=0.35$ (left) and $w / b=0.45$ (right). Dashed lines represent the estimate of the released heat by the hydration model.

It is observed that the cumulated released heats reach comparable values within a few days for all mixes. Hence, the NS particles do not seem to lead to higher ultimate hydration 
degree, but they improve the hydration kinetics. This observation is consistent with the filler effect. Indeed, by introducing an equivalent Blaine specific surface of $5000 \mathrm{~m}^{2} / \mathrm{kg}$ for the NS particles, compared to $2000 \mathrm{~m}^{2} / \mathrm{kg}$ for the silica fumes, the effect of the NS particles on the cumulated released heat is properly modelled (Fig. 1.3). The raise of the heat flux has already been observed by isothermal calorimetry up to 72 hours [1] and 40 hours [6], even if variable amounts of superplasticizer were introduced. It has also been reported in the absence of superplasticizer and attributed to the increased number of nucleation sites [30. Furthermore, it is also observed in [30 that cement pastes containing NS release more heat prior to $11 \mathrm{~h}$ and less heat between $11 \mathrm{~h}$ and $72 \mathrm{~h}$ : these results are consistent with the final cumulated heat being nearly unaffected by the substitution of cement by NS particles. The threshold of $11 \mathrm{~h}$ introduced in 30 is depicted as the beginning of the diffusion-controlled deceleration stage and the lower released heat after $11 \mathrm{~h}$ is attributed to the diffusion coefficient being smaller due to denser hydration products. Nevertheless, since the maximum heat flux occurs earlier for cement pastes containing NS particles, it is likely that the diffusioncontrolled deceleration stage starts before $11 \mathrm{~h}$, thus weakening the claim that NS particles influence the hydration kinetics in various ways. Indeed, separating the acceleration stage and the diffusion-controlled stage of hydration is an involved task and can hardly be achieved by setting a fixed threshold.

\subsubsection{Thermogravimetric analysis}

While isothermal calorimetry is an experiment of choice for getting insight on the hydration degree at early age, thermogravimetric analysis is able to track the amount of Porlandite, bound water and calcite in the cement paste at later ages. Thermogravimetric analysis have been performed on the different pastes at time $t=1,3,7,28,90$ days after mix. To a certain extend, the considered testing procedure is similar to that described by Pane \& Hansen [31]: the sample is ground, then soaked in methanol for a week to stop hydration reactions, then dried for a week in a desiccator (using silica gel). Finally, the sample is heated at a rate of $10^{\circ} \mathrm{C} / \mathrm{min}$ and the mass loss is recorded as a function of temperature and derived using finite differences. Finally, a Gaussian filter is applied for smoothing (Fig. 1.4). Nevertheless, vacuum was not applied as the samples were dried, resulting in a significant mass loss below $140^{\circ} \mathrm{C}$ and the amount of bound water cannot be correctly estimated. In addition, the methanol likely reacted with the Portlandite [32, 33, thus leading to a reduced amount of Portlandite and abnormally high estimated amount of calcite. As a result, the measured TGA curve cannot be treated to recover quantitative estimates of the amount of bound water, calcite and Portlandite. Nevertheless, all derivatives feature a significant peak related to the dehydration of Portlandite and a minimal amount of Portlandite can be segmented using the tangential method [34. As a consequence, there is a significant amount of Portlandite in all the considered cement pastes (Tab. 1.3) up to 90 days and all these cement pastes likely feature alkaline pore solutions: none of these pastes can be described as a low $\mathrm{pH}$ cement paste. In addition, since the amount of carbonates in the binder is known, a corrected estimate of the Portlandite content can be computed based on the measured amount of Portlandite and calcite (Fig. 1.5). While the corrected Portlandite content of the reference cement paste increases, those of binary mixes where part of the cement is substituted by amorphous silica are stable of decrease. This is a clue that a pozzolanic reaction occurs and it is visibly stronger for $5 \%$ NS particles than for $7.4 \%$ silica fume. Lastly, it is visible that the Portlandite content at later ages decreases with the weight fraction of NS particles. The Portlandite content also slightly increases as the water/binder ratio increases from $w / b=0.35$ to $w / b=0.45$, which can be due to the effect of moisture on the hydration kinetics. By looking at figure 1.5 , it seems that the corrected Portlandite content still slightly decreases between 7 and 90 days for the mix containing $5 \% \mathrm{NS}$ at $w / b=0.45$. The authors must acknowledge that their results may not sound enough for this trend to be significant. Nevertheless, decrease or consumption of Portlandite between 7 and 28 days related to NS are reported in references [2, 4, 6]. While NS particles could be expected to react rapidly, it must be recalled that the temperature is kept low, at $20^{\circ} \mathrm{C}$ and that the activation energy of the pozzolanic reaction is higher than that of hydration reactions.

\section{Effet of nano-silica on the rheology of the cement paste}

It is known that NS particles increase the water demand of a cement paste and this effect is often directly related to their particular specific surface, as for other pozzolans [35]. Incorporating such small particles in a cementitious mix is expected to improve the particle packing density, which is often associated to better rheological properties [36]. Nevertheless, 


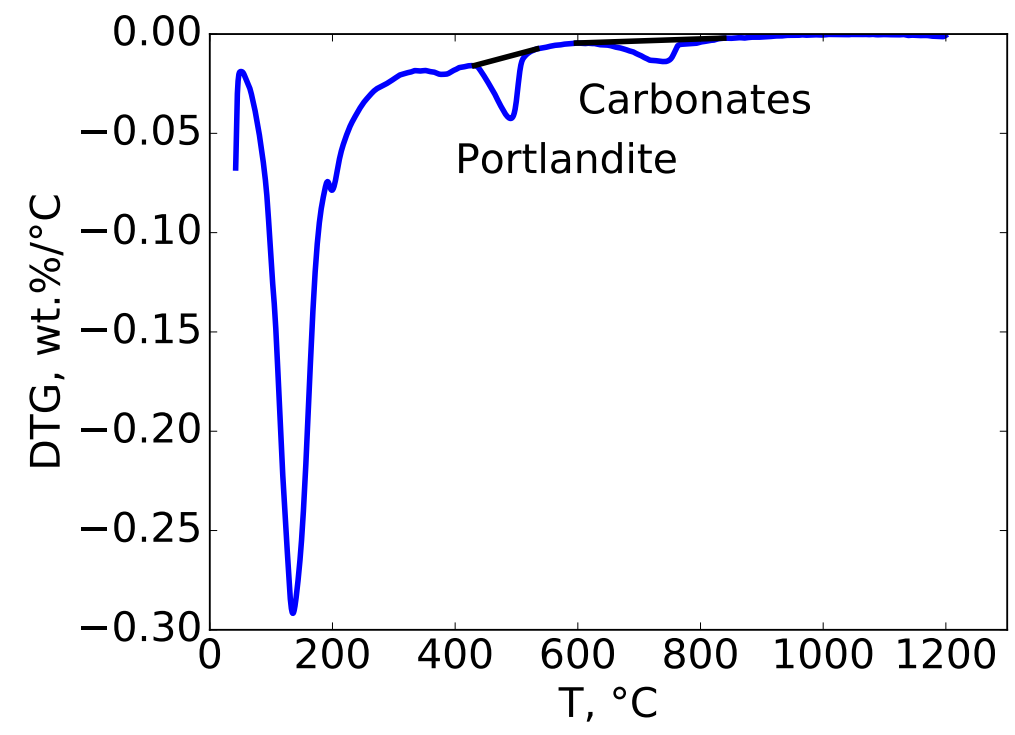

Figure 1.4: A thermogravimetric analysis is performed on C950NS050, $w / b=0.45$ at 90 days. The derivative of the mass per mass of binder with respect to temperature is plotted as a function of the temperature. Peaks of Portlandite and Carbonates are visible.

Table 1.3: Minimal amounts of Portlandite measured by thermogravimetric analysis, in weight per weight of binder (\%). These amounts are likely much lower than the actual amount of Portlandite due to carbonation occurring as the samples were prepared.

\begin{tabular}{c|ccccc|ccccc} 
& \multicolumn{9}{|c}{$w / b=0.35$} \\
age, days & 1 & 3 & 7 & 28 & 90 & 1 & 3 & 7 & 28 & 90 \\
\hline C1000 & 7.79 & 8.98 & 10.39 & 10.37 & 10.43 & 8.83 & 11.34 & 13.64 & 12.64 & 13.69 \\
C985NS015 & 7.39 & 7.46 & 8.45 & 8.9 & 11.58 & 8.46 & 9.56 & 12.02 & 12.17 & 12.99 \\
C970NS030 & 6.25 & 6.44 & 6.82 & 6.79 & 9.31 & 8.32 & 7.79 & 8.89 & 8.17 & 12.12 \\
C950NS050 & & & & & & 4.47 & 5.78 & 5.4 & 6.53 & 7.72 \\
C926SF074 & 6.04 & 8 & 8.27 & 9.09 & 8.65 & 6.96 & 9.8 & 9.69 & 11.47 & 10.99 \\
C811FA189 & 7.36 & 9.06 & 6.81 & 9.29 & 8.07 & 8.05 & 11.33 & 7.38 & 11.55 & 10.96 \\
C776FA191NS033 & & & & & & 6.3 & 4.9 & 6.64 & 6.06 & 8.03
\end{tabular}
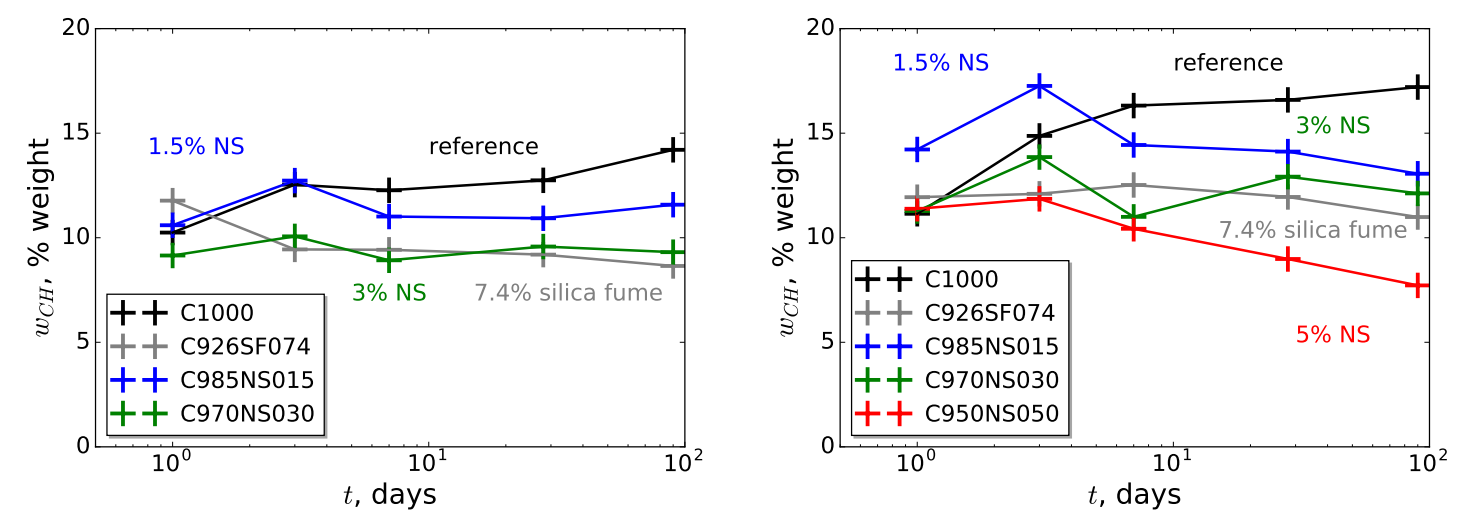

Figure 1.5: Corrected weight of Portlandite in cement pastes per weight of binder as a function of time. Left: $w / b=0.35$, right: $w / b=0.45$

since NS particles raise the viscosity of the mix, the interactions between these particles must be investigated. To this end, the DLVO theory [11, 12] can be applied to describe the competition between Van der Waals attraction and electrostatic repulsion between particles (Fig. 2.1).

Modelling the interparticle potential in cement suspensions explains the observed flocculation of cement particles [37. Indeed, the zeta potential of cement grains is related to the mineral phases of the Bogue composition, as silicate phase $\left(\mathrm{C}_{3} \mathrm{~S}, \mathrm{C}_{2} \mathrm{~S}\right)$ possess negative charges and aluminate hydrates covering $\mathrm{C}_{3} \mathrm{~A}$ and $\mathrm{C}_{4} \mathrm{AF}$ are positively charged [38]. Nevertheless, given the high ionic strength, $\mathrm{pH}$, calcium and sulfate concentration of the pore solution, these charges remain limited and the zeta potentials are in range $-7 \mathrm{mV}-+12 \mathrm{mV}$ 


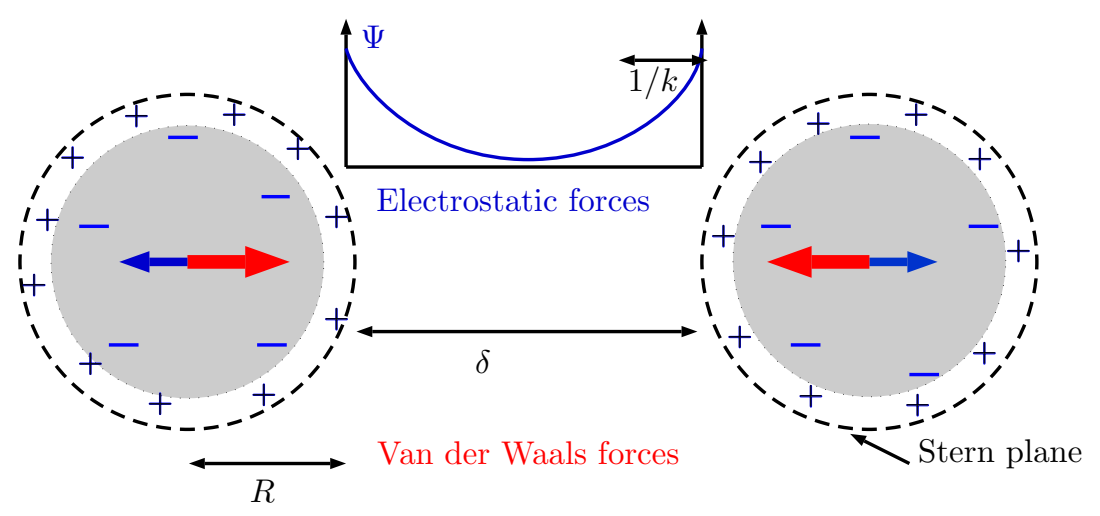

Figure 2.1: Attractive Van der Waals forces and the repulsive electrostatic forces between two particles are displayed. The pictured situation corresponds to that of NS particles in a cement paste as proposed herein: despite the surface charges, the potential rapidly decreases due to the small Debye length $1 / k$ and the Van der Waals attraction overcomes the electrostatic repulsion for all distances $\delta$, thus triggering the flocculation.

[39], thus triggering the flocculation. The zeta potentials of mineral additions such as quartz, limestone and fly ash also remain in this range [39]. Indeed, both cement hydrates and silica fume possess a small positive surface charge in spite of the high $\mathrm{pH}$ due to the high concentration of calcium [40]. Lastly, the zeta potential is strongly affected by the $\mathrm{pH}$ and concentration of ions in solutions: for instance, zeta potential of $+35 \mathrm{mV}$ have been observed on type F fly ash suspensions saturated by Portlandite [41]: a lot of calcium ions are adsorbed on the surface of the particles. On the contrary, in a fresh cement paste, the calcium ions compete for adsorption against sodium and potassium ions, thus reducing the zeta potential. A practical model coupling the DLVO theory and equilibrium of complexation reactions has been designed to study the stability of $\mathrm{C}-\mathrm{S}-\mathrm{H}$ [15, 16] and pyrogenic silica [13, 14]. It is hereby coupled to an improved model predicting the concentrations of ions in the pore solution of the cement paste [17. While the range of Van der Waals attraction increases with the radius of the particles, that of electrostatic repulsion is tightly related to the concentrations of ions in the pore solution. Hence, though the flocculation of cement particles and classical pozzolanic additions is well-known, the flocculation of smaller NS particles needs to be investigated. To this end, the DLVO theory is to be briefly recalled in the next section.

\subsection{The DLVO theory}

The DLVO theory [11, 12] is intended to explain the stability of colloidal suspensions. Attractive Van der Waals forces promote flocculation while repulsive electrostatic forces due to surface charges on the particles may prevent this collapse of suspended particles into aggregates.

\subsection{Van der Waals interaction energy}

The Van der Waals interaction energy between two spherical particles of radii $R_{1}$ and $R_{2}$ separated by a distance $\delta$ writes [42]:

$W_{v d w}=-\frac{H}{12}\left[\frac{4 R_{1} R_{2}}{\delta^{2}+2 \delta R_{1}+2 \delta R_{2}}+\frac{4 R_{1} R_{2}}{\delta^{2}+2 \delta R_{1}+2 \delta R_{2}+4 R_{1} R_{2}}+2 \ln \left(\frac{\delta^{2}+2 \delta R_{1}+2 \delta R_{2}}{\delta^{2}+2 \delta R_{1}+2 \delta R_{2}+4 R_{1} R_{2}}\right)\right]$

where $H$ is the Hamaker constant. If the distance between the particles is small $\left(\delta<<R_{1}\right.$ and $\delta<<R_{2}$ ), it is approximated to:

$$
W_{v d w} \approx-\frac{H}{6 \delta} \frac{R_{1} R_{2}}{R_{1}+R_{2}}
$$

On the contrary, if the distance between the particle is large $\left(\delta>>R_{1}\right.$ and $\left.\delta>>R_{2}\right)$, the classical trend of the Van der Waals interaction energy is recovered:

$$
W_{v d w} \approx-\frac{16 H R_{1}^{3} R_{2}^{3}}{9 \delta^{6}}
$$

The Hamaker constant is set according to the model of Flatt [4] for colloidal particles in water:

$$
H=0.341310^{-20} \mathrm{~J}\left(\rho_{1}-1\right)\left(\rho_{2}-1\right)
$$

where $\rho_{1}$ and $\rho_{2}$ are the densities of the particles. 


\subsection{Electrostatic interaction}

Particles in liquids feature a surface charge related to the formation of an electric double layer. As a result, there is an electrostatic force between particles which can be be attractive or repulsive depending on their surface charges. Hogg et. al. [44 have derived the interaction energy per surface unit between two planes at potential $\Psi_{1}, \Psi_{2}$, the potential in the bulk solution being null. The only requirement is that the potentials are low enough $\left(q_{i} \Psi(r)<<\right.$ $k_{B} T$, where $q_{i}$ is the charge of ions, $k_{B}=1.38064852 e-23 \mathrm{JK}^{-1}$ is the Boltzmann constant and $T$ is the temperature) so that the Poisson's equation can be linearised as performed by Debye and Hückel (Appendix A). The interaction energy per surface unit $W_{e, p l a n e}$ writes:

$$
W_{e, p l a n e}(\delta)=k \epsilon_{0} \epsilon_{r}\left[\frac{1}{2}\left(\Psi_{1}^{2}+\Psi_{2}^{2}\right)\left(1-\frac{\operatorname{ch}(k \delta)}{\operatorname{sh}(k \delta)}\right)+\Psi_{1} \Psi_{2} \frac{1}{\operatorname{sh}(k \delta)}\right]
$$

where $\epsilon_{0}=8.854187817 e-12 \mathrm{~A}^{2} \cdot \mathrm{s}^{4} \mathrm{~kg}^{-1} \cdot \mathrm{m}^{-3}$ is the permittivity of vacuum and $\epsilon_{r}$ is the relative permeability of water $(\approx 80), k=\sqrt{2 I /\left(k_{B} T \epsilon_{0} \epsilon_{r}\right)}$ is the inverse of the Debye length, $I=0.5 \sum_{i} q_{i}^{2} n_{i}^{b}$ is the ionic strength and $\delta$ is the distance between the planes. If the particles are close to one another $\left(\delta<<R_{1}, R_{2}\right)$, the Derjaguin approximation [45] can be applied to estimate the interaction energy between the spheres starting from the equation above [44]. Hence, the electrostatic force between the particles writes:

$$
F(\delta)=2 \pi \frac{R_{1} R_{2}}{R_{1}+R_{2}} W_{e, p l a n e}(\delta)
$$

Consequently, the interaction energy between two particles can be estimated as:

$$
W_{e}(\delta)=\int_{\delta}^{+\infty} F(\tau) \mathrm{d} \tau=\pi \epsilon_{0} \epsilon_{r} \frac{R_{1} R_{2}}{R_{1}+R_{2}}\left[\left(\Psi_{1}^{2}+\Psi_{2}^{2}\right) \ln \left(1-e^{-2 k \delta}\right)+2 \Psi_{1} \Psi_{2} \ln \left(\frac{1+e^{-k \delta}}{1-e^{-k \delta}}\right)\right]
$$

The potentials $\Psi_{1}, \Psi_{2}$ at the surface of the particles are tightly related to the adsorption affinity of the ions.

\subsection{Potential at the surface of particles}

The potential at the surface of cement particles, mineral additions and C-S-H are computed according to the complexation surface model where the surface is in equilibrium with the bulk solution [13. Indeed, it is assumed that the potential of a particle is left unmodified by the proximity of other particles. This assumption is reasonable if and only if the distance between the particles is larger than the Debye length. In this case, interactions between particles are often estimated by applying a superposition principle. The models of Milonjić [14 and Viallis-Terrisse et al. [15, 16] are respectively applied for the surface of pyrogenic silica and C-S-H: three complexation reactions can occur at the silanol $\mathrm{SiOH}$ site (Fig. 2.2). Each reaction introduces a new metal complex and a new equilibrium constant: $\mathrm{SiO}^{-}, \mathrm{SiOCa}^{+}$and $\mathrm{SiOM}$, where $\mathrm{M}$ refers to $\mathrm{K}$ or Na (Tab. 2.1, 2.2). These metal complexes are responsible for the surface charge $\sigma$ of the particle. Let $n_{s}$ be the number of site at the surface of the particle per unit surface and $n_{\mathrm{SiOH}}, n_{\mathrm{SiO}^{-}}, n_{\mathrm{SiOCa}^{+}}, n_{\mathrm{SiOM}}$ be the number of each metal complex per unit surface. Due to the conservation of the number of sites, $n_{s}=n_{\mathrm{SiOH}}+n_{\mathrm{SiO}^{-}}+n_{\mathrm{SiOCa}^{+}}+n_{\mathrm{SiOM}}$. In addition the surface charge $\sigma$ which triggers the potential is $\sigma=e\left(-n_{\mathrm{SiO}^{-}}+n_{\mathrm{SiOCa}^{+}}\right)$. Solving the Debye and Hückel equation for a single surface at $z=0$, Gouy and Chapman introduced a diffuse double layer where the potential $\Psi(z)$ decreases exponentially with the distance to the surface $\left(\Psi(z)=\Psi_{0} e^{-k z} \forall z>0\right.$ where $k$ is the Debye length) [46, 47]. The electric field derives from this potential and the discontinuity of the normal component of the electric field is related to the surface charge:

$$
\sigma=\epsilon_{0} \epsilon_{r} k \Psi_{0}
$$

The previous equation is consistent with the Grahame equation in case of small potentials. As a consequence to this equation, the charge can be substituted by the potential $\Psi_{0}$. An equilibrium constant is defined for each complexation reaction. The activities of metal complexes $a_{\mathrm{SiOH}}$ are equal to their surface densities $n_{\mathrm{SiOH}}$ and the activities of ions $a_{i}=n_{i} \gamma_{i}$ in solution at zero potential are evaluated according to the extended Debye-Hückel equation for natural water [48, 49]:

$$
\ln \left(\gamma_{i}\right)=-\frac{q_{i}^{2}}{8 \pi \epsilon_{0} \epsilon_{r} k_{b} T} \frac{k}{1+k a_{0}^{i}}+\ln (10) b^{i} I
$$


Table 2.1: Complexation reaction at the surface of C-S-H according to the model of ViallisTerrisse et. al. [15, 16]. The site surface density of C-S-H is $n_{s}=2 / 41 \AA^{-2}$.

\begin{tabular}{|c|c|c|}
\hline reaction & equilibrium constant & value \\
\hline $\mathrm{SiOH} \leftrightarrow \mathrm{SiO}^{-}+\mathrm{H}^{+}$ & $K_{1}=\frac{a_{S i O^{-}} a_{H^{+}}}{a_{S i O H}} e^{\frac{-e \Psi}{k_{B} T}}$ & $10^{-12.3}$ \\
\hline $\begin{aligned} \mathrm{SiOH}+\mathrm{Ca}^{2+} & \leftrightarrow \mathrm{SiOCa}^{+}+\mathrm{H}^{+} \\
\mathrm{SiOH}+\mathrm{M}^{+} & \leftrightarrow \mathrm{SiOM}+\mathrm{H}^{+}\end{aligned}$ & $\begin{array}{c}K_{2}=\frac{a_{S i O C a^{+}} a_{H^{+}}}{a_{S i O H} a_{C a^{2}}+} e^{\frac{e \Psi}{k_{B} T}} \\
K_{3}=\frac{a_{S i O M} a_{H^{+}}}{a_{S i O H} a_{M^{+}}}\end{array}$ & $\begin{array}{c}10^{-9.4} \\
10^{-12.1}\end{array}$ \\
\hline
\end{tabular}

Table 2.2: Complexation reaction at the surface of pyrogenic silica according to the model of Milonjić [13, 14] at $298 \mathrm{~K}$. The site surface density of pyrogenic silica is $n_{s}=0.0785 \AA^{-2}$. *The equilibrium constant for the complexation of calcium at the surface of silica is set by assuming that the calcium concentration zeroing the charge is similar to that of $\mathrm{C}-\mathrm{S}-\mathrm{H}$ reported in [15, 16] $(2 \mathrm{mmol} / \mathrm{L})$.

$$
\begin{aligned}
& \text { reaction equilibrium constant value } \\
& \mathrm{SiOH} \leftrightarrow \mathrm{SiO}^{-}+\mathrm{H}^{+} \quad K_{1}=\frac{a_{\mathrm{SiO}^{-}} a_{H^{+}}}{a_{\mathrm{SiOH}}} e^{\frac{-e \Psi}{k_{B} T}} \quad 10^{-7.2}
\end{aligned}
$$

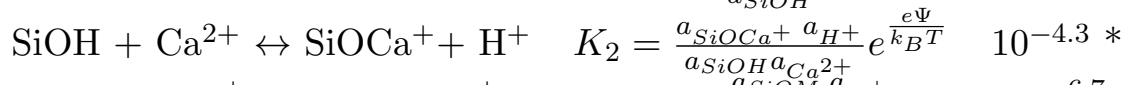

$$
\begin{aligned}
& \mathrm{SiOH}+\mathrm{M}^{+} \leftrightarrow \mathrm{SiOM}+\mathrm{H}^{+} \quad K_{3}=\frac{a_{S i O M} a_{H^{+}}}{a_{S i O H} a_{M^{+}}} \quad 10^{-6.7}
\end{aligned}
$$

Table 2.3: The effective diameters of ions [50, 48, 49]

\begin{tabular}{ccc} 
ion & effective diameter $a_{0}^{i}, \AA$ & $b^{i}, \mathrm{~L}^{\mathrm{mol}}{ }^{-1}$ \\
\hline $\mathrm{H}^{+}$ & 9 & \\
$\mathrm{OH}^{-}$ & 3.5 & 0 \\
$\mathrm{~K}^{+}$ & 3 & 0 \\
$\mathrm{Na}^{+}$ & 4 & 0.015 \\
$\mathrm{Ca}^{2+}$ & 6 & 0.075 \\
$\mathrm{SO}_{4}^{2-}$ & 4 & 0.165 \\
& & -0.04
\end{tabular}




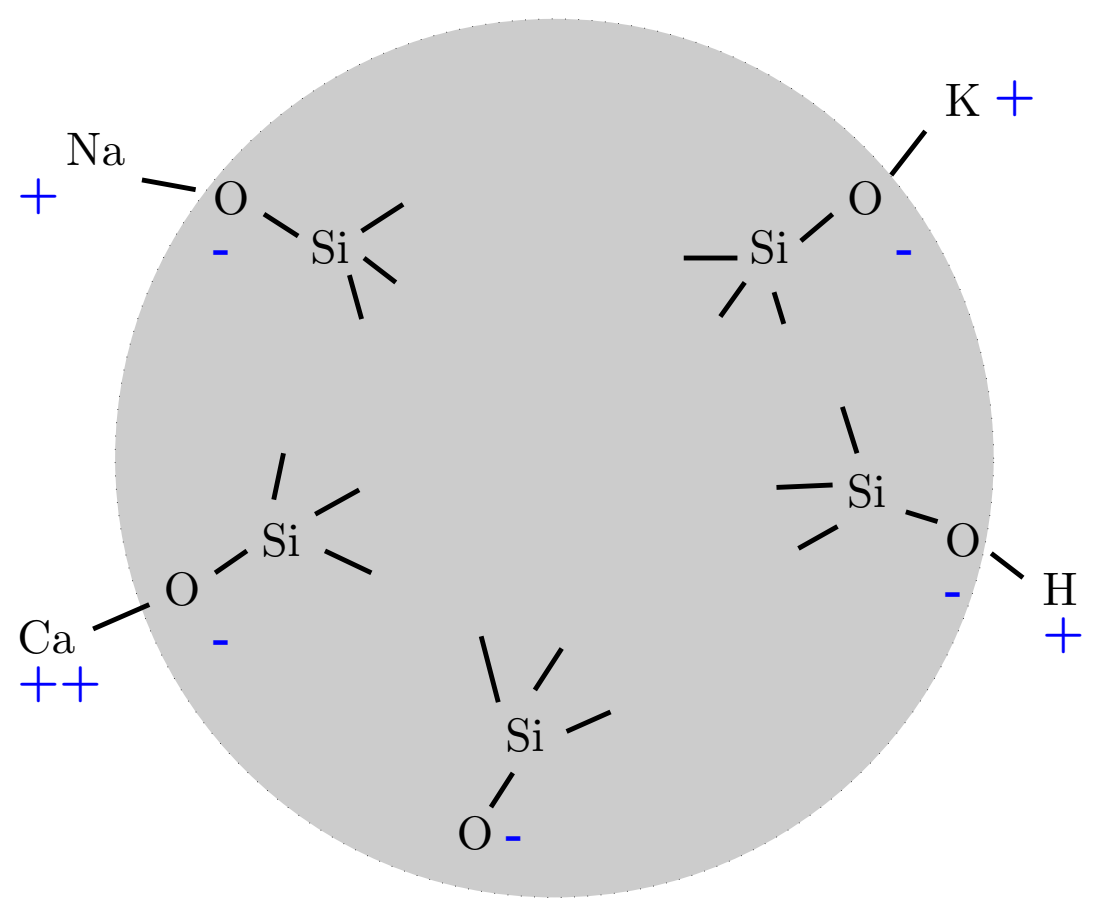

Figure 2.2: The considered metal complex at the surface of amorphous NS particles 14. Depending on number and kind of formed complex, the particle may acquire a surface charge.

where $a_{0}^{i}$ is the effective diameter of the ion [50] and $b^{i}$ is an additional fit parameter [48, 49] (Tab. 2.3).

If the concentrations of all ions in the solution are known, the set of previous equations (equilibrium constants, conservation of surface sites, link between surface charge and potential) can be solved to retrieve an estimate of the potential of particles. Therefore, an estimate of the concentration of ions in the pore solution of the cement paste will be described in the next section.

\subsection{Concentrations of ions in the pore solution of a cement paste}

The concentrations of ions in the pore solution of a cement paste are estimated according to the model of Eijk and Brouwers [17]. As inputs, this model requires an estimate of the hydration degree and the total water-filled porosity $\phi$, including the gel porosity in the $\mathrm{C}$ $\mathrm{S}-\mathrm{H}$. Indeed, the formula of $\mathrm{C}-\mathrm{S}-\mathrm{H}$ is considered as the one of saturated globule $\mathrm{C}_{1.7} \mathrm{SH}_{1.8}$ in the colloid model of C-S-H CM-II [51] and the remaining water must be accounted for in the water-filled porosity. Let $j / c$ be the mass mix ratios and $\rho_{j}$ be the density of each species of the mix (including water $w$ ). $m_{N a} / c$ and $m_{K} / c$ are respectively the mass fractions of $\mathrm{Na}$ and $\mathrm{K}$ in the cement. The concentration of these ions in mol/L evolves due to their release from the clinker and sulphates and their adsorption on the formed hydrates [17]:

$$
\begin{aligned}
{\left[N a^{+}\right] } & =\frac{\left(0.35+0.65 \alpha\left(1-b_{N a} /(w / c) \alpha\right)\right) m_{N a} / c}{M_{N a} \phi \sum_{j} \frac{j / c}{\rho_{j}}} \\
{\left[K^{+}\right] } & =\frac{\left(0.70+0.30 \alpha\left(1-b_{K} /(w / c) \alpha\right)\right) m_{K} / c}{M_{K} \phi \sum_{j} \frac{j / c}{\rho_{j}}}
\end{aligned}
$$

where $b_{N a}=0.3$ and $b_{K}=0.27$. Additional ions from fly ashes or initial water can also be incorporated in these estimates. Since the cement paste is saturated of Portlandite $\mathrm{Ca}(\mathrm{OH})_{2}$ and water, the solubility products can be introduced:

$$
\left[\mathrm{Ca}^{2+}\right]\left[\mathrm{OH}^{-}\right]^{2} \gamma\left(\mathrm{Ca}^{2+}\right)\left(\gamma\left(\mathrm{OH}^{-}\right)\right)^{2}=K_{C H} 10^{S I}
$$

The saturation index of Portlandite is set to $S I=0.5$ to retrieve the supersaturation observed in [52. The concentration of hydrogen ions and the $\mathrm{pH}$ can be estimated according to the self-ionisation constant of water:

$$
\left[H^{+}\right]\left[O H^{-}\right] \gamma\left(H^{+}\right) \gamma\left(O H^{-}\right)=10^{-p H}\left[O H^{-}\right] \gamma\left(O H^{-}\right)=K_{W}
$$

where the self-ionisation constant of water $K_{W}$ depends on temperature and pressure [53]. The model of Eijk and Brouwers does not account for the sulfate ions $\mathrm{SO}_{4}^{2-}$ from the gypsum and it triggers an overestimation of the $\mathrm{pH}$ in the early age. Since gypsum is not completely 
dissolved in the fresh cement paste, it is assumed in the present model that the solution is saturated with respect to gypsum as long as gypsum is present:

$$
\left[\mathrm{Ca}^{2+}\right]\left[\mathrm{SO}_{4}^{2-}\right] \gamma\left(\mathrm{Ca}^{2+}\right) \gamma\left(\mathrm{SO}_{4}^{2-}\right)=K_{\text {gypsum }}
$$

As the gypsum is consumed, the solubility products of ettringite $K_{a f t}$ and monosulfoaluminate $K_{a f m}$ [54] can be combined to form a new solubility product $K_{a f t / a f m}$ involving the activity of calcium and sulphate ions:

$$
\left(\left[\mathrm{Ca}^{2+}\right]\left[S \mathrm{SO}_{4}^{2-}\right] \gamma\left(\mathrm{Ca}^{2+}\right) \gamma\left(S \mathrm{~S}_{4}^{2-}\right)\right)^{2}=K_{\text {aft } / \text { afm }}
$$

This solubility product corresponds to the reaction:

$$
\mathrm{C}_{6} \mathrm{AS}_{26} \leftrightarrow \mathrm{C}_{4} \mathrm{AS} \mathrm{SH}_{6}+2 C a_{a q}^{2+}+2 S O_{4 a q}^{2-}+20 \mathrm{H}
$$

The solubility products at standard temperature $\left(T^{0}=298.15 \mathrm{~K}\right)$ and pressure $\left(P^{0}=0.1 \mathrm{MPa}\right)$ are reported in table 2.5. In addition, these solubility products can be computed for other temperatures [54] and pressures according to the van Hoff equation. Assuming that the molar heat capacities and the molar volumes of the chemical species are independent from the temperature and the pressure, the solubility product is computed as:

$\ln (K)(T, P)=\ln (K)\left(T^{0}, P^{0}\right)+\frac{\Delta_{r} H^{0}-T^{0} \Delta_{r} C p^{0}}{R}\left(\frac{1}{T^{0}}-\frac{1}{T}\right)+\frac{\Delta_{r} C p^{0}}{R} \ln \left(\frac{T}{T^{0}}\right)-\frac{\Delta_{r} V^{0}}{R T}\left(P-P^{0}\right)$

where the enthalpy of reaction $\Delta_{r} H^{0}$, change of heat capacity $\Delta_{r} C p^{0}$ and change of molar volume $\Delta_{r} V^{0}$ reported in table 2.5 have respectively been computed starting from those of the chemical species (Tab. 2.4).

Table 2.4: Enthalpy of formation, heat capacity and molar volume of each chemical species

\begin{tabular}{|c|c|c|c|c|c|}
\hline Species & formula & $\Delta_{f} H, \mathrm{~kJ} \cdot \mathrm{mol}^{-1}$ & $C_{p}, \mathrm{~J} \cdot \mathrm{mol}^{-1} \cdot \mathrm{K}^{-1}$ & $V \mathrm{~cm}^{3} \cdot \mathrm{mol}^{-1}$ & source \\
\hline liquid water & $\mathrm{H}_{2} \mathrm{O}$ & -285.830 & 75.291 & 18.0685 & 68,69 \\
\hline Portlandite & $\mathrm{Ca}(\mathrm{OH})_{2}$ & -986.085 & 87.49 & 33.056 & 68, 69] \\
\hline gypsum & $\mathrm{Ca}\left(\mathrm{SO}_{4}\right) \cdot 2 \mathrm{H}_{2} \mathrm{O}$ & -2022.63 & 186.02 & 74.69 & 68. 69] \\
\hline ettringite $26 \mathrm{H}_{2} \mathrm{O}$ & & $-17535+6^{*} 285.830$ & $2174-6^{*} 75.291$ & $707-6^{*} 18.0685$ & 70], $32 \mathrm{H}_{2} \mathrm{O}$ \\
\hline monosulphoaluminate $6 \mathrm{H}_{2} \mathrm{O}$ & & $-8750+6^{*} 285.830$ & $942-6 * 75.291$ & $309-6^{*} 18.0685$ & 70], $12 \mathrm{H}_{2} \mathrm{O}$ \\
\hline $\mathrm{H}^{+}$ao & $\mathrm{H}^{+}$ & 0 & 0 & 0 & 68.55 \\
\hline $\mathrm{OH}^{-}$aо & $\mathrm{OH}^{-}$ & -229.994 & -148.5 & -5.3 & 68.55 \\
\hline $\mathrm{Ca}^{2+}$ ao & $\mathrm{Ca}^{2+}$ & -542.83 & 42 & -17.7 & 68.55 \\
\hline $\mathrm{SO}_{4}{ }^{2-}$ ao & $\mathrm{SO}_{4}{ }^{2-}$ & -909.27 & -293 & 14.5 & 68 \\
\hline
\end{tabular}
at $25^{\circ} \mathrm{C}$ and $0.1 \mathrm{MPa}$. For ion species, the apparent molar volume of ions are sourced from [55].

Table 2.5: Considered reactions, solubility products, enthalpy of reactions, change of heat capacity and volume change of reactions at $25^{\circ} \mathrm{C}$ and $0.1 \mathrm{MPa}$.

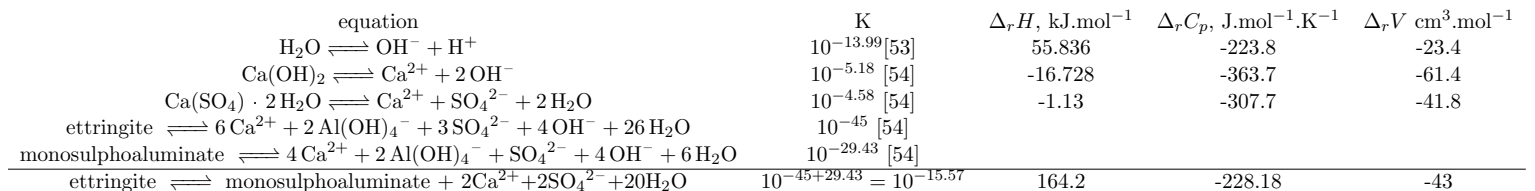

The apparent molar volume of $\mathrm{SO}_{4}{ }^{2-}$ is deduced from the partial molar volume of solutes $\mathrm{Na}_{2} \mathrm{SO}_{4}, \mathrm{~K}_{2} \mathrm{SO}_{4}, \mathrm{ZnSO}_{4}, \mathrm{NiSO}_{4}$ reported in [55]. The partial molar heat capacity of calcium ions is set to $42 \mathrm{~J} \cdot \mathrm{mol}^{-1} \cdot \mathrm{K}^{-1}$ so as to comply with the expression of the solubility product of Portlandite reported in [56] on page 115. More accurate descriptions of the molar heat capacities and molar volumes as functions of temperature and pressure [57, 58] are to be considered if the explored environmental conditions strongly differs from the standard temperature and pressure.

Lastly, the neutrality of the solution is to be ensured:

$$
\left[\mathrm{Na}^{+}\right]+\left[\mathrm{K}^{+}\right]+\left[\mathrm{H}^{+}\right]+2\left[\mathrm{Ca}^{2+}\right]=\left[\mathrm{OH}^{-}\right]+2\left[\mathrm{SO}_{4}^{2-}\right]
$$

A fixed point algorithm is designed to solve this set of equations. Indeed, if the ionic strength is known, all activities can be computed and the concentrations of all ions can be expressed as a function of $\left[\mathrm{OH}^{-}\right]$thanks to equilibrium constants. These expressions are then substituted in the equation 19 to compute $\left[\mathrm{OH}^{-}\right]$as the positive root of a polynomial of order 4. Finally, a new estimate of the ionic strength is built according to the newly computed concentrations and the procedure can be repeated until convergence. 
Table 2.6: Minicone slump tests of different cement pastes. The minicone is $150 \mathrm{~mm}$ heigh, the lower and upper diameters being respectively $100 \mathrm{~mm}$ and $50 \mathrm{~mm}$.

\begin{tabular}{|c|c|c|c|c|c|}
\hline & density, $\mathrm{g} / \mathrm{cm}^{3}$ & spread diameter, mm & $\begin{array}{l}\text { heigh, mm } \\
w / b=0.35\end{array}$ & shear strengh, $\mathrm{Pa}$ & $\begin{array}{l}\text { segregation diam- } \\
\text { eter, } \mathrm{cm}\end{array}$ \\
\hline C1000 & 2.02 & 145 & 45 & 514 & 160 \\
\hline C926SF074 & 1.99 & 115 & 90 & 1041 & 300 \\
\hline \multirow[t]{2}{*}{ C811FA189 } & 1.94 & 155 & 50 & 549 & 150 \\
\hline & & & $w / b=0.45$ & & \\
\hline C1000 & 1.89 & 280 & 10 & 28 & 6 \\
\hline C985NS015 & 1.89 & 105 & 100 & 1070 & 277 \\
\hline C926SF074 & 1.86 & 235 & 30 & 68 & 17 \\
\hline C811FA189 & 1.83 & 260 & 20 & 41 & 10 \\
\hline
\end{tabular}

\subsection{Application to the stability of $C-S-H$ and nano-silica suspensions}

\subsubsection{Minicone test}

The yield stress $\tau_{0}$ can be estimated starting from the slump test [59]. The expression of the estimated yield stress depends on the final heigh $H$ and radius $R$ of the sample:

$$
\begin{array}{lll}
\tau_{0}=\frac{225 \rho g \Omega^{2}}{128 \pi^{2} R^{5}} & H<<R \\
\tau_{0} & =\rho g \frac{1}{\sqrt{3}} H & H>>R
\end{array}
$$

where $g$ is the gravity, $\rho$ is the density of the paste, $\Omega$ is the volume of the cone and $H_{0}$ its heigh. Between these extreme situations, the estimated yield stress $\tau_{0}$ is computed as the minimum of both formula. Then, starting from this yield stress $\tau_{0}$, a critical diameter $d_{c}$ can be defined to estimate whether of not segregation can occur to an aggregate of density $\rho_{a}$ 60]:

$$
d_{c}=\frac{18 \tau_{0}}{\left|\rho_{a}-\rho\right| g}
$$

The results of the slump tests are reported in table 2.6, along with the estimated shear strengths and segregation diameters. Only one mix containing NS particles could be tested: for other mixes, either the paste cannot be properly cast in the minicone or it sticks to it (Fig. 2.3). Nevertheless, the rheology of the cement paste containing $1.5 \%$ weight of NS in the binder at water to cement ratio 0.45 proves very different from that of other mixes of water to cement ratio 0.45 . Indeed, it is similar to that of cement pastes of water to cement ratio 0.35. As a result, NS particles clearly make the paste more viscous. By performing tests on various cement paste, it has been proposed that $3 \mathrm{D}$ printing requires a shear strength in the range $300-900 \mathrm{~Pa} 61$. While the pure cement paste $(\mathrm{w} / \mathrm{c}=0.45)$ is obviously too fluid to be printed, substituting only $1.5 \%$ weight of NS makes it slightly too viscous! To perform compressive strength tests, vibrating the samples right after casting is required for most mixes incorporating NS particles.

\subsubsection{Outcome of the proposed model}

The proposed model of the interparticle potential is consistent with the experimental findings. Indeed, despite their smaller size, the NS particles are expected to flocculate since this potential steadily decreases as the spacing between particles decreases (Fig. 2.4). The attractive Van der Waals forces always wins against the electrostatic repulsion, even if the range of Van der Waals forces is smaller for nanoparticles than for silica fume. It is related to the very small range of electrostatic forces, that is the Debye length.

The model is run on the cement reported in table 1.1, using a water to cement ratio of 0.45 and considering the weight fraction of $\mathrm{K}_{2} \mathrm{O}$ and $\mathrm{Na}_{2} \mathrm{O}$ to respectively be $0.97 \%$ and $0.08 \%$ (Fig. 2.4). Owing to the very high ionic strength $(I=0.45 \mathrm{~mol} / \mathrm{L})$, the Debye length is as small as $1 / k=0.45 \mathrm{~nm}$ at the hydration degree of $1 \%$. This small Debye length is combined to small particle potentials : the potential of both C-S-H globules and NS particles is about $+1.5 \mathrm{mV}$. Concentrations of $\mathrm{K}^{+}, \mathrm{Na}^{+}, \mathrm{OH}^{-}, \mathrm{Ca}^{2+}$ and $\mathrm{SO}_{4}^{2-}$ respectively are $330 \mathrm{mmol} / \mathrm{L}$, $21 \mathrm{mmol} / \mathrm{L}, 189 \mathrm{mmol} / \mathrm{L}, 5 \mathrm{mmol} / \mathrm{L}$ and $86 \mathrm{mmol} / \mathrm{L}$, thus inducing a $\mathrm{pH}$ of 13 and a conductivity of $5.3 \mathrm{~S} / \mathrm{m}$. The conductivity of the pore solution is estimated starting from the ion concentrations and the ionic strength 62.

The sulphate resistant cement reported in [52] ( $\mathrm{C}_{3} \mathrm{~S}=61 \%, \mathrm{C}_{2} \mathrm{~S}=18 \%, \mathrm{C}_{3} \mathrm{~A}=3.9 \%, \mathrm{C}_{4} \mathrm{AF}=5.8 \%$, $\mathrm{C} \overline{\mathrm{C}}=3.7 \%, \mathrm{~S} \overline{\mathrm{S}}=3.6 \%)$ contains much less alkali $\left(\mathrm{K}_{2} \mathrm{O}=0.22 \%, \mathrm{~N}_{2} \mathrm{O}=0.13 \%\right)$. As a result, the ionic strength of a cement paste of water-to-cement ratio 0.4 at a hydration degree of $1 \%$ is 


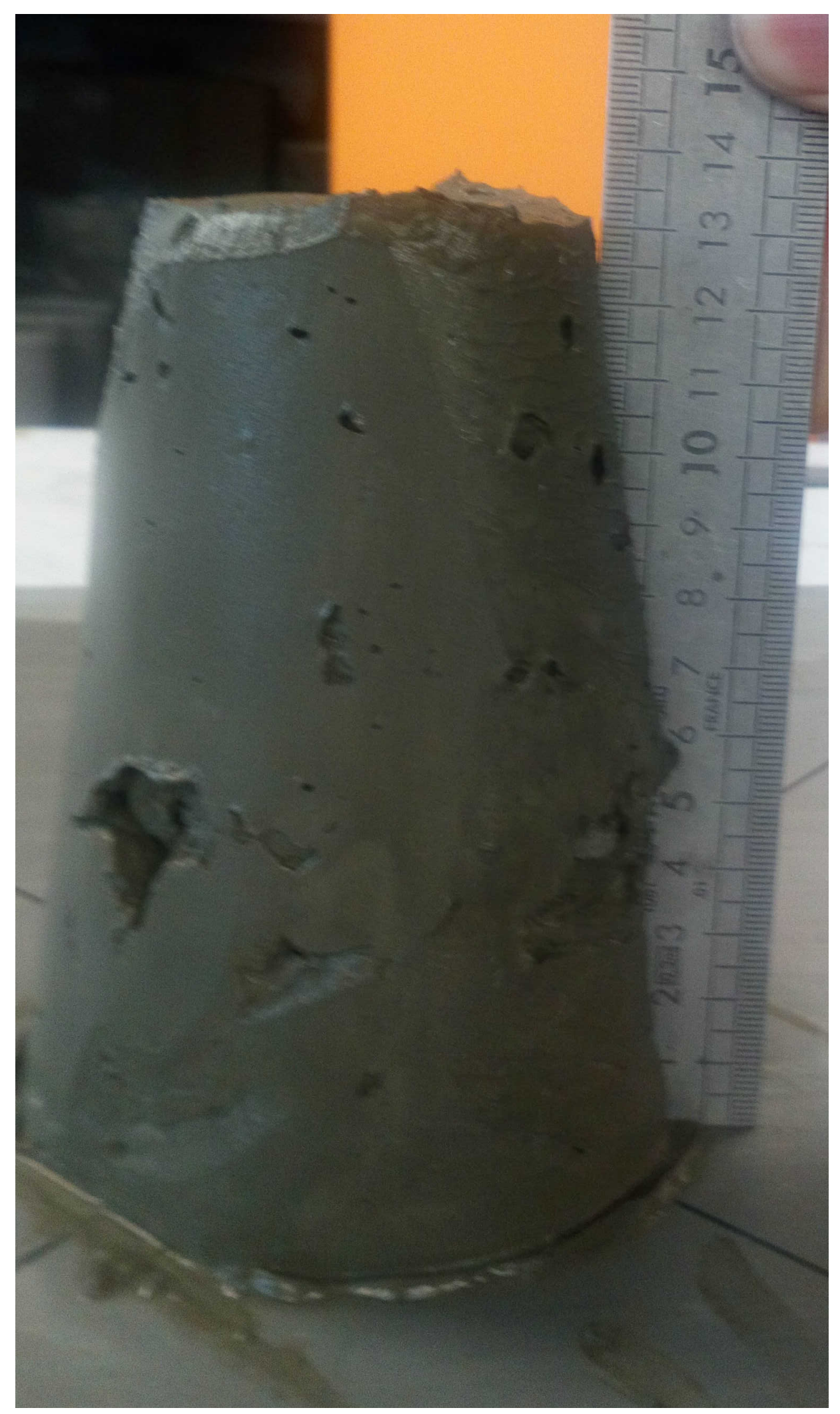

Figure 2.3: A minicone test is performed on the fresh cement paste C985NS015 featuring $1.5 \% \mathrm{NS}$ at water-to-cement ratio 0.35 . The initial heigh of the minicone is $150 \mathrm{~mm}$ and the final height is about $130 \mathrm{~mm}$ : this cement paste does not significantly flow under its own weight.

lower, at $0.177 \mathrm{~mol} / \mathrm{L}$ and the Debye length is larger at $1 / k=0.7 \mathrm{~nm}$. The potential at the surface of particles becomes about $+14 \mathrm{mV}$ for both $\mathrm{C}-\mathrm{S}-\mathrm{H}$ and $\mathrm{SiO}_{2}$. Nevertheless, despite the extended range and strength of repulsive electrostatic interactions, the NS particles are still expected to flocculate. The positive potential of the particles is related to a larger calcium concentration $(12 \mathrm{mmol} / \mathrm{L})$. Concentrations of $\mathrm{K}^{+}, \mathrm{Na}^{+}, \mathrm{OH}^{-}, \mathrm{Ca}^{2+}$ and $\mathrm{SO}_{4}^{2-}$ respectively are $82 \mathrm{mmol} / \mathrm{L}, 37 \mathrm{mmol} / \mathrm{L}, 101 \mathrm{mmol} / \mathrm{L}, 12 \mathrm{mmol} / \mathrm{L}$ and $21 \mathrm{mmol} / \mathrm{L}$, thus inducing a $\mathrm{pH}$ of 12.8 and a conductivity of $2.6 \mathrm{~S} / \mathrm{m}$. These concentrations are consistent with those provided in [52. The proposed model also accounts for the observed slight increase of $\mathrm{pH}$ between 2.4 and 6 days attributed to the depletion of gypsum. Indeed, at 6 days, the estimated concentrations respectively becomes $111 \mathrm{mmol} / \mathrm{L}, 78 \mathrm{mmol} / \mathrm{L}, 197 \mathrm{mmol} / \mathrm{L}, 3 \mathrm{mmol} / \mathrm{L}$ and $0.5 \mathrm{mmol} / \mathrm{L}$. Again, the agreement with the experimental measurements of concentrations reported in $[52$ 
is to be noticed. Considering a higher water-to-cement ratio of 0.55 could enable a stable suspension of silica fume and NS at $1 \%$ hydration degree as the interparticle potential features a local maximum (Fig. 2.4). Indeed, the ionic strength is lower $(I=0.147 \mathrm{~mol} / \mathrm{L})$ and the Debye length increases to $1 / k=0.8 \mathrm{~nm}$. The calcium concentration is raised to $15 \mathrm{mmol} / \mathrm{L}$ and the $\mathrm{pH}$ is 12.8 , the potential of both $\mathrm{C}-\mathrm{S}-\mathrm{H}$ and NS being close to $18 \mathrm{mV}$.

The amount of calcium adsorbed at the surface of $\mathrm{C}-\mathrm{S}-\mathrm{H}$ globules is significant. The amount of calcium in the globule is evaluated using the formula $\mathrm{C}_{1.7} \mathrm{SH}_{1.8}$ for a globule of density $2.604 \mathrm{~g} / \mathrm{cm}^{3}$ [51]. As a result, the amount of calcium adsorbed at the surface of a spherical C-S-H globule of diameter $4.2 \mathrm{~nm}$ would represent about $20 \%$ of the calcium forming its chemical structure. It decreases to about $11 \%$ at $60^{\circ} \mathrm{C}$. The temperature and pressure does not affect the main outcome of the model. Indeed, the NS particles are expected to flocculate at temperature in the range $5^{\circ} \mathrm{C}-60{ }^{\circ} \mathrm{C}$, pressure in the range $0.1 \mathrm{MPa}-10 \mathrm{MPa}$ and waterto-cement ratio lower than 0.45 .
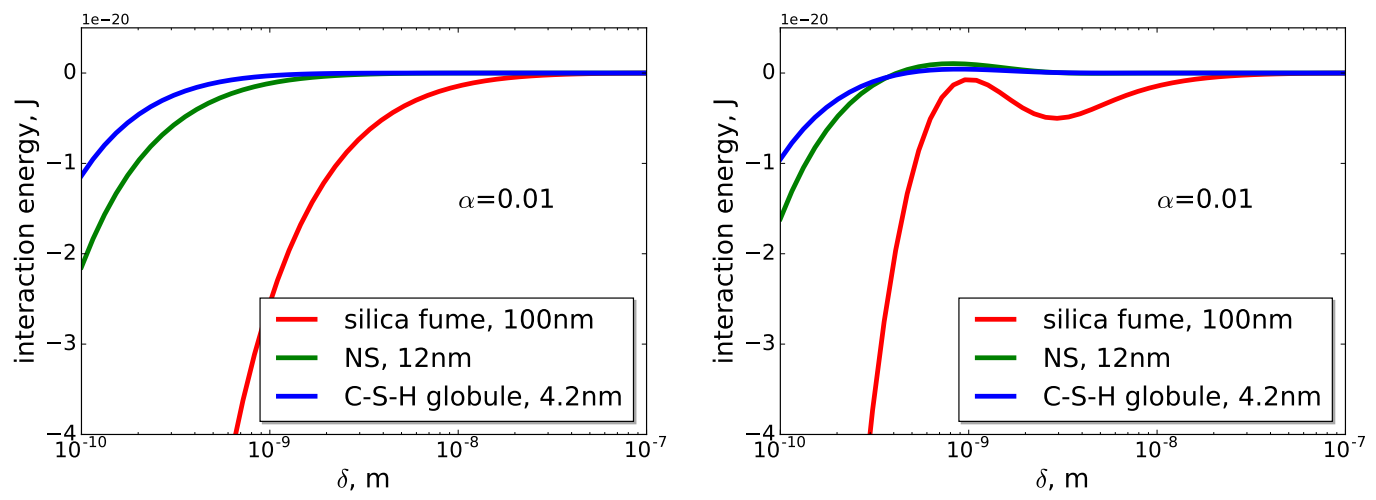

Figure 2.4: The interaction energy between particles is estimated. Left : the considered pore solution is that of a cement paste of water to cement ratio 0.45 and hydration degree $\alpha=1 \%$. The absence of local maximum implies flocculation. Right : the considered pore solution is that of the sulfate resistant cement paste of water to cement ratio 0.55 and hydration degree $\alpha=1 \%$.

\subsubsection{Limitations of the model}

The proposed model introduces a single potential, as if the Stern layer was thin. Therefore, differences between the surface potential, the Stern potential and the Zeta potential are not discussed. To be more accurate, the estimated potential would correspond to the Stern potential, while the charge includes both the charge of the particle and that of the complexed ions. Moreover, the computed interactions can be erroneous as the distance between the particles becomes comparable to the thickness of the Stern layer which is related to the effective diameter of the complexed ions and lies in the range $4-8 \AA$ [63]. As a result, the proposed plots are limited to spacing larger than $1 \mathrm{~nm}$ and the proposed model is useless if the morphology of the C-S-H gel is studied by molecular dynamics as in 64. But it does not affect the evidence brought by the model: at spacing higher than $1 \mathrm{~nm}$, Van der Waals attraction prevails over the electrostatic repulsion and the suspension flocculates.

The flocculated particles can be assumed to form floccules, that are loosely packs of particles attracting each other. Even if the interaction potential featured a minimum at $1 \mathrm{~nm}$, the volume fraction $c_{p}$ of the particles of diameter $d$ in the resulting gel could be estimated as $c_{p}=0.32 d^{3} /(d+0.5 \mathrm{~nm})$, leaving $c_{p}=28 \%$ for $\mathrm{NS}(d=12 \mathrm{~nm})$ and $c_{p}=22 \%$ for C-S-H globules $(d=4.2 \mathrm{~nm})$, the volume fraction of $32 \%$ being sourced from sedimentation experiments on cement [37. The porosity in the C-S-H can later be filled due to the formation of new globules. Regarding the rheology, the porosity in the NS floccules can be described as a water demand, valued at $w / N S \approx 1 \mathrm{~g} / \mathrm{g}$. For instance, in the mix C950NS050 at $w / b=0.45$, once the water trapped in NS floccules is subtracted, the remaining water occupies $49 \%$ of the volume, as in a cement paste of $w / b=0.3$. Indeed, the rheological properties of that blended cement paste is comparable to that of a pure cement paste featuring a very low $w / b$ : the slump is small, segregation of aggregates is not expected and bleeding unlikely.

The proposed model is limited to Van-der-Waals and electrostatic interactions. As a result, it does not account for steric and electrostatic repulsions which would occur if superplasticizer such as polycarboxylate was added to the mix. The repulsive effect of superplasticizer and organic admixture on the rheology of cement paste is modelled as a Stern layer in 65. The thickness on such a layer is comparable to the length of the considered polymeric chains, 
Table 3.1: Compressive strengths of the different cement paste as a function of time. Uncertainties are computed using $95 \%$ confidence intervals of the 6 tests, unless specified otherwise in parenthesis. The porosity $\phi$ relative to the trapped air is estimated by comparing the measured density of the sample to its expected value.

\begin{tabular}{cc|ccccc} 
& $\phi, \%$ & \multicolumn{5}{|c}{$w / b=0.35$} \\
age, days & & 1 & 3 & 7 & 28 & 90 \\
\hline C1000 & 0 & $39.1 \pm 1.8(4)$ & $63.3 \pm 2.6$ & $70.5 \pm 2.2$ & $77.9 \pm 4.1$ & $87.8 \pm 2.8$ \\
C985NS015 & $0-2$ & $46.8 \pm 1.4$ & $62.5 \pm 1.4$ & $64.5 \pm 3.0$ & $75.0 \pm 3.9$ & $78.4 \pm 2.8$ \\
C970NS030 & $1-2$ & $41.1 \pm 2.5$ & $55.1 \pm 1.8$ & $49.8 \pm 4.9$ & $74.0 \pm 3.2$ & $113.6 \pm 7.0$ \\
C926SF074 & 0 & $36.8 \pm 0.5$ & $56.2 \pm 1.6$ & $63.8 \pm 1.5$ & $80.0 \pm 1.9$ & $87.7 \pm 2.9$ \\
C811FA189 & $0-1$ & $28.9 \pm 0.6$ & $50.5 \pm 1.7$ & $61.9 \pm 1.2$ & $73.3 \pm 2.0$ & $92.0 \pm 3.3$ \\
\hline & & \multicolumn{5}{c}{$w / b=0.45$} \\
age, days & & 1 & 3 & 7 & 28 & 90 \\
\hline C1000 & 0 & $20.3 \pm 0.2$ & $43.2 \pm 1.1(3)$ & $51.3 \pm 0.5$ & $59.8 \pm 2.6$ & $68.6 \pm 1.5$ \\
C985NS015 & $0-1$ & $31.7 \pm 0.7$ & $45.7 \pm 1.6$ & $51.8 \pm 1.6$ & $55.7 \pm 1.0$ & $62.8 \pm 1.8$ \\
C970NS030 & $1-2$ & $36.2 \pm 1.1$ & $48.8 \pm 2.3$ & $56.1 \pm 2.6$ & $64.8 \pm 0.4$ & $103.8 \pm 4.1$ \\
C950NS050 & $2-5$ & $27.4 \pm 1.8$ & $37.3 \pm 0.6$ & $41.6 \pm 2.9$ & $44.2 \pm 3.5$ & $49.6 \pm 2.5$ \\
C926SF074 & $0-1$ & $20.0 \pm 0.2$ & $38.9 \pm 0.8$ & $45.0 \pm 1.1(4)$ & $57.8 \pm 1.1$ & $70.6 \pm 2.2$ \\
C811FA189 & $0-1$ & $13.06 \pm 0.2$ & $31.9 \pm 1.0$ & $42.5 \pm 1.2$ & $50.5 \pm 2.1(3)$ & $67.9 \pm 1.9$ \\
C776FA191NS033 & $1-2$ & $25.4 \pm 2.4(4)$ & $33.6 \pm 2.0$ & $44.6 \pm 2.0$ & $56.2 \pm 1.8$ & $62.1 \pm 4.8$
\end{tabular}

valued at about $100 \mathrm{~nm}$. Hence, the range of these repulsions is likely much larger than that of considered electrostatic repulsions and Van der Waals attractions by at least one order of magnitude. The height of that repulsive barrier likely depends on the number of polymer chains adsorbed on the particles, likely related to the concentrations of ions in the solution and the functional groups of the considered polymer. The range of the steric repulsion is likely related to the length of the polymeric chains: it suggests that short-sized polymer might be sufficient to deflocculate NS particles, since the range of the Van der Waals attraction is related to their radii. The adsorption of a superplasticizer could be modelled by adding it as a new complex and measuring the corresponding equilibrium constants. Nevertheless, the molecule of the superplasticizer is likely larger than the Debye length, thus questioning the use of both the equation of Hogg et al. and the Gouy-Chapman theory. In addition, the complexation of calcium on the superplasticizer would also have to be accounted for 66.

On the one hand, the high specific surface of nano-silicate improves the hydration kinetics. On the other hand, the nano-silicate particles strongly alter the rheology of the cement paste. As a result, the effect of nano-silicate particles on the progressive increase of the compressive strength is expected to be complex.

\section{The convoluted effect of nano-silicate on the development of the compressive strength}

\subsection{Compressive strength as a function of time}

The compressive strengths of the different cement pastes are measured at $t=1,3,7,28$ and 90 days according to EN 196-1 and respectively reported in table 3.1 . $4 \times 4 \times 16 \mathrm{~cm}^{3}$ prismatic samples are cast, unmolded at the age of 1 day, stored in sealed plastic bags in a moist room until the strength tests are performed. Three 3-point bending tests are performed and 6 uniaxial compression tests are performed on the resulting cubic halves. Unsurprisingly, the compressive strength increases with age and decreases with the water-to-binder ratio. For water-to-binder ratio of $w / b=0.35$, it is observed that the compressive strength decreases as NS is substituted to cement. On the contrary, for $w / b=0.45$, the compressive strength of cement pastes containing NS particles is much higher than that of the reference (up to $36 \mathrm{MPa}$ compared to $20 \mathrm{MPa}$ at the age of 1 day). Indeed, it increases up to $3 \%$ weight of NS particles and decreases at 5\% NS particles. On the one hand, the acceleration of cement hydration by NS particles explains the increase of compressive strength. On the other hand, the effect of NS particles on the rheology of the cement paste explains the decrease of compressive strength. Indeed, the trapped air in samples incorporating NS particles is much higher than that of the reference. Finally, the secant Young moduli of the cement pastes have been measured at different ages and reported in figure 3.1. Two $11 \mathrm{~cm} \times 22 \mathrm{~cm}$ cylinders are loaded for most of the mixes using an extensometer with 3 LVDT sensors and the difference between the identified Young moduli is about 1GPa. It is also shown that the relationship between the compressive strength and the elastic stiffness is not significantly altered by incorporating NS particles: both are still predominantly dependent on the porosity. 


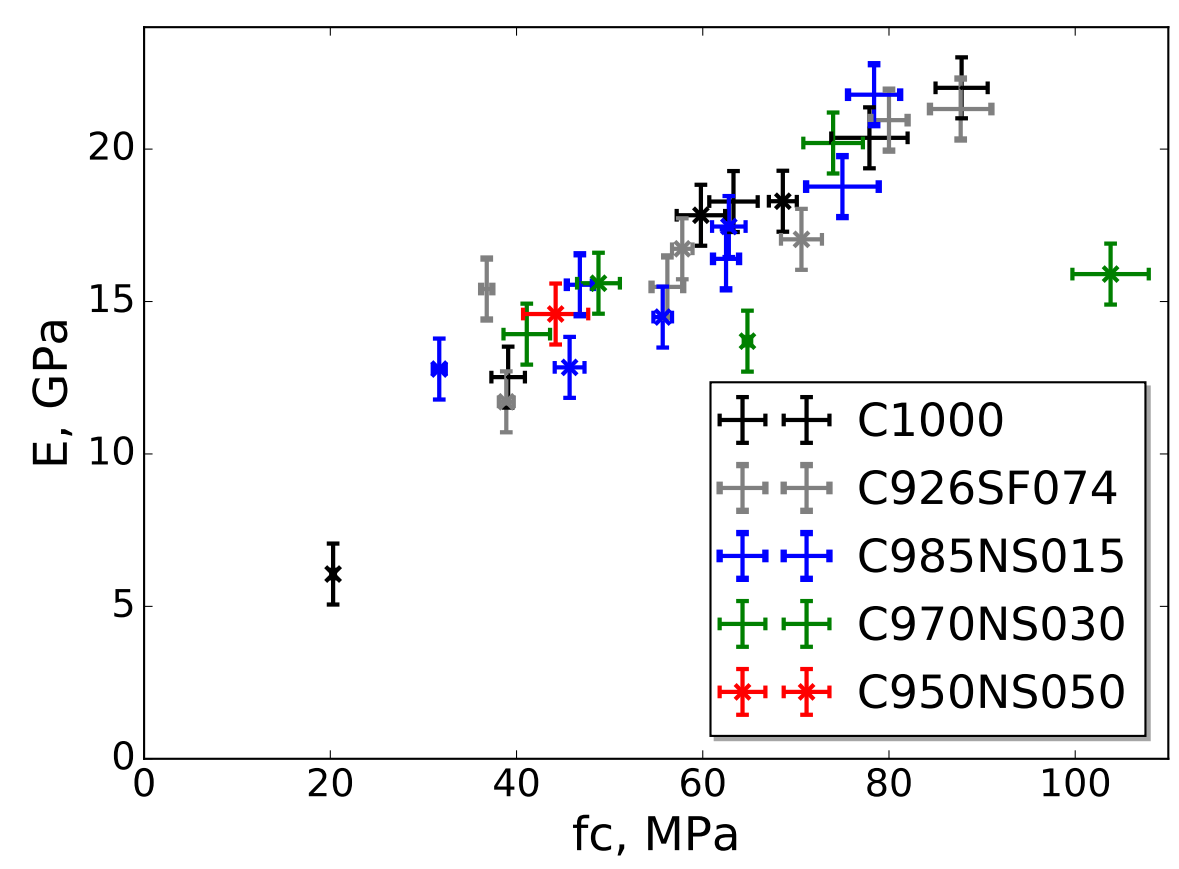

Figure 3.1: The Young modulus is plotted versus the compressive strength for different cement pastes tested at different age and water to cement ratios of 0.35 and 0.45 (crosses).

For thick concrete structures like bridges or containment building, accelerating the release of heat by incorporating NS could trigger an inappropriate rise of the internal temperature. Substituting the cement by other mineral additions such as limestone fillers or fly ash could solve such an issue and reduce the environmental footprint of the cement paste.

\subsection{Formulating a ternary blend containing NS and fly ash}

To investigate ternary blends incorporating NS particles, fly ash has been introduced. The weight fraction of NS particles in the binder is $3.3 \%$ while that of fly ash is $19.1 \%$, leaving $77.6 \%$ as the weight fraction of the cement. On the one hand, the NS particles are expected to accelerate the hydration of the cement. On the other hand, the dilution effect of fly ash is expected to mitigate this acceleration. By performing isothermal calorimetry, it is shown that the heat released by the exothermic reactions in the ternary blend is actually comparable to that of the reference (Fig. 3.2). Moreover, the heat released by the ternary blend is significantly higher than that of cement blended with fly ash: the NS particles clearly accelerates the chemical reactions. Regarding thermogravimetric analysis (Fig. 3.3), the ternary mix features estimated amount of Portlandite lower than that of the reference, due to either the dilution effect or pozzolanic reactions. Since the Portlandite content in the ternary mix reaches a maximum and then globally decreases, a pozzolanic reaction is likely occurring.

In addition, due to the pozzolanic reactions, the mixes containing fly ash are expected to reach a compressive strength similar to that of the reference at later age, as observed on table 3.1. Moreover the ternary blend also features a compressive strength higher than that of the pure cement paste at one day. Nevertheless, the compressive strength of the ternary blend is not as high as that of the pure cement paste after one day. Indeed, the fly ash slowly reacts and the fresh cement paste containing NS and fly ash is more viscous than pure cement paste, to the point that the trapped air is increased, leading to the observed lower compressive strength at 90 days. The ternary blended cement paste is also slightly less dense than the corresponding pure cement pastes, by about $4-5 \%$.

This ternary blend featuring a development of the compressive strength similar to that of the reference cement would enable a $11 \%$ decrease of $\mathrm{CO}_{2}$ emissions related to the reduction of cement content, the emissions related to the NS particles being accounted for. Indeed the carbon emission would decrease to $0.775 \mathrm{t} / \mathrm{t}$. Nevertheless, even if the prices of cement, NS particles and fly ash were respectively $200 € / \mathrm{t}, 3 € / \mathrm{kg}$ and $30 € / \mathrm{t}$, the price per weight of the ternary binder would be about $260 € / t$ and the cost of emission reductions would be about $650 €$ per ton of $\mathrm{CO}_{2}$, that is well above the actual price of $\mathrm{CO}_{2}$ in Europe (about $10 € / \mathrm{t}$, as of 2018). Nevertheless, these figures are very sensitive to the prices of materials and the present study is limited to isothermal conditions at $20^{\circ} \mathrm{C}$ while precast and thick concrete structures experience a rise of the internal temperature. The hydration model [25] 


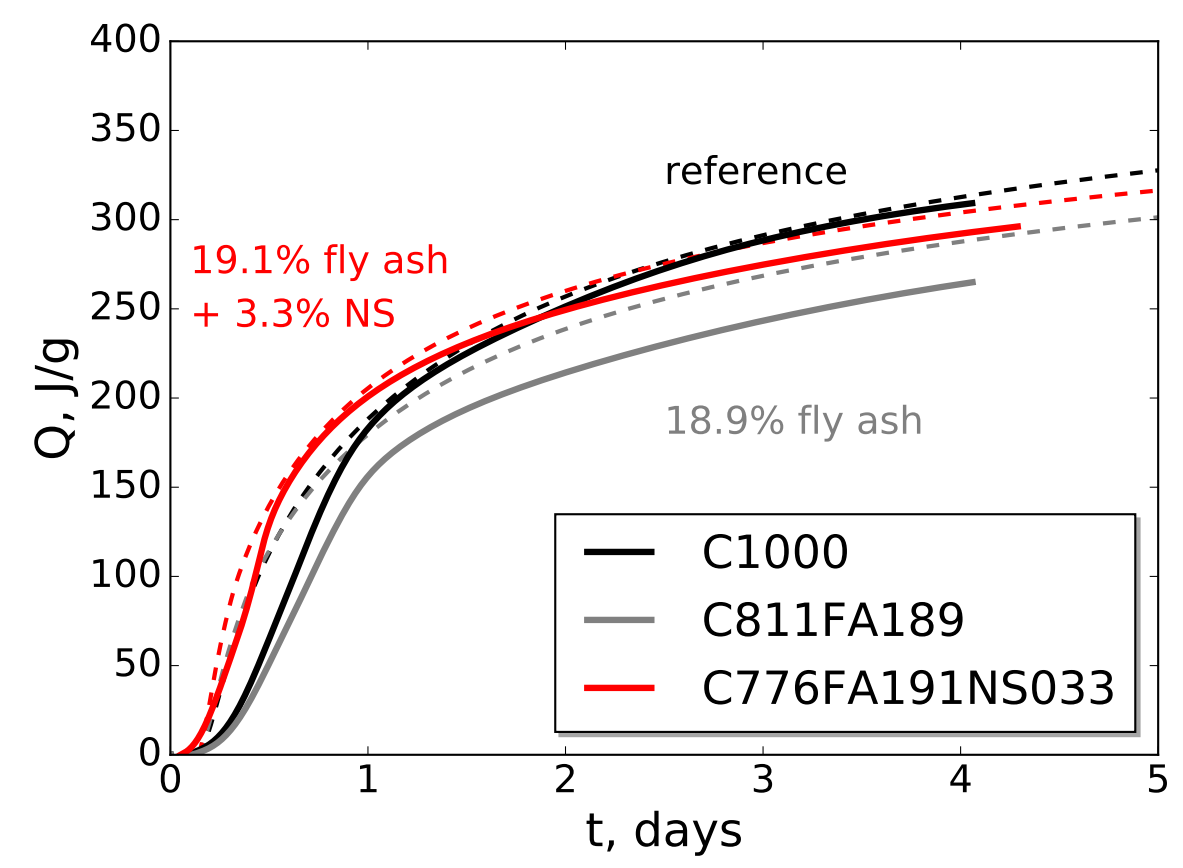

Figure 3.2: Cumulated released heat per weight of binder during isothermal calorimetry tests, $w / b=0.45$. Dashed lines represent the estimate of the released heat by the hydration model $[25]$.

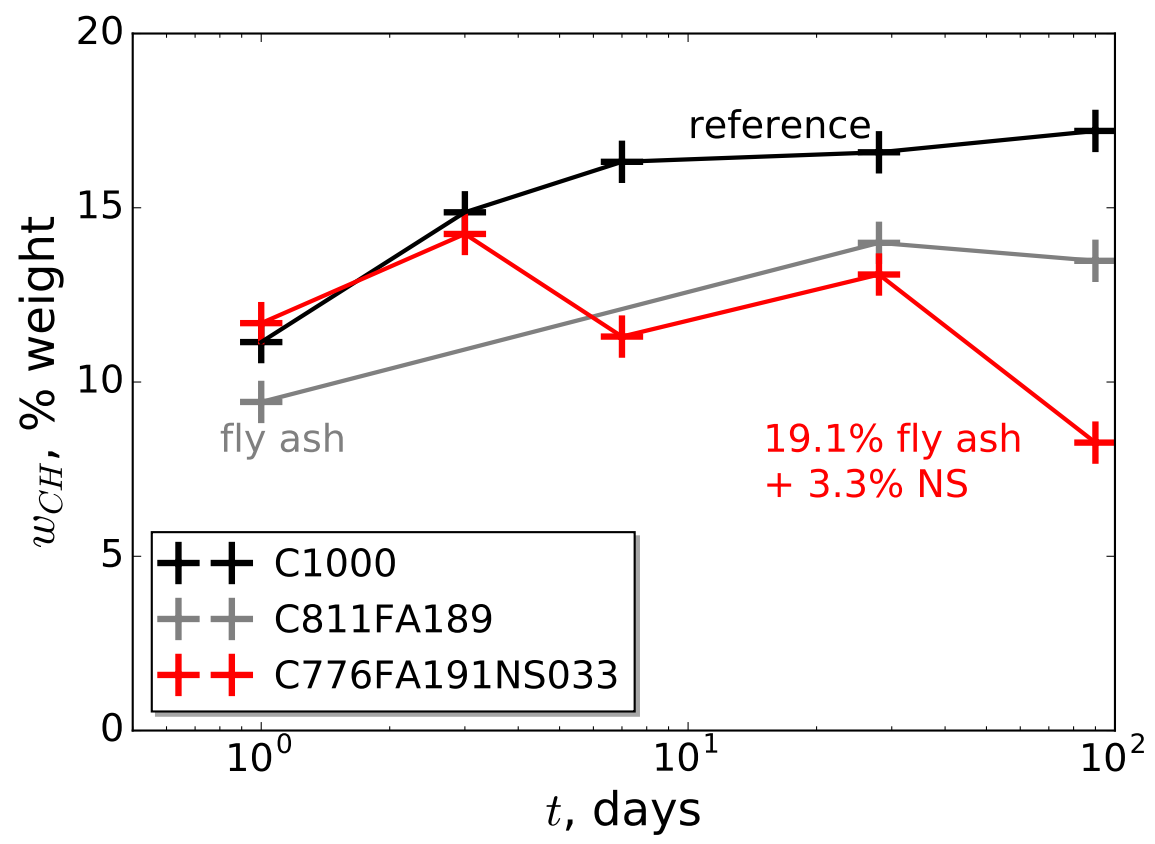

Figure 3.3: Corrected weight of Portlandite in cement pastes per weight of binder as a function of time. $w / b=0.45$

is able to estimate the temperature rise during semi-adiabatic tests as measured according to standards EN 196-9 [67]. To simulate these tests $360 \mathrm{~g}$ of binder, 1000g of sand and 162g of water are virtually introduced in a Langavant calorimeter of parameters $a=80 \mathrm{~J} \cdot \mathrm{h}^{-1} \cdot \mathrm{K}^{-1}$ and $b=0.277 \mathrm{~J} \cdot \mathrm{h}^{-1} \cdot \mathrm{K}^{-2}$. The estimated temperature is plotted on figure 3.4 while substituting cement by fly ash is expected to reduce the maximum temperature, NS particles are expected to induce a slight increase of the maximum temperature for the ternary blend.

\section{Conclusion}

Nanosilica particles induce an accelerated hydration of the cement which is made obvious by isothermal calorimetry. This effect is attributed to their specific surface and can be quantitatively accounted for in a hydration model. Moreover, it is shown that cement paste incorporating 5\% NS particles contains a reduced but significant amount of Portlandite at 90 days: NS particles are more efficient than silica fumes as a pozzolanic reactant, but the 


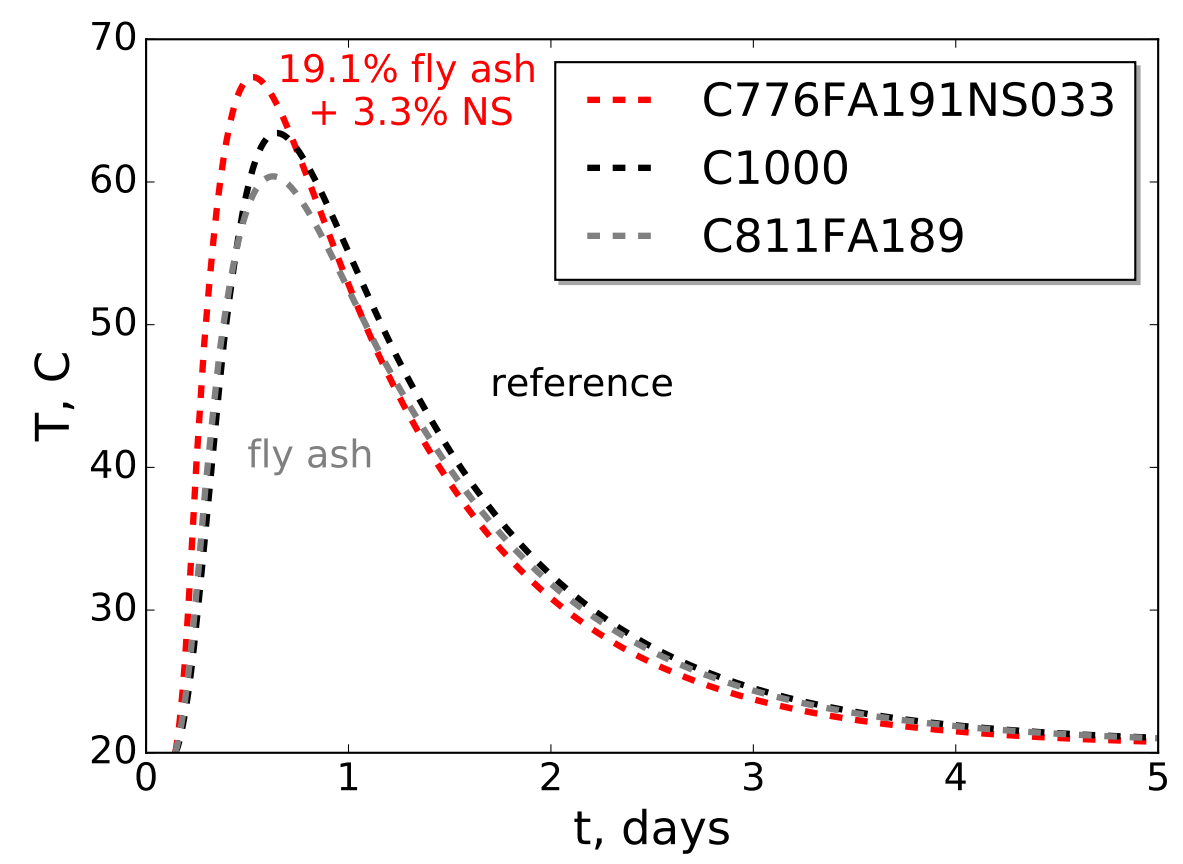

Figure 3.4: Temperatures during semi-adiabatic calorimetry tests are estimated by using the hydration model [25].

pore solution likely remains highly alkaline even if $5 \%$ weight of NS particles are incorporated in the mix. Therefore, such cement pastes could be considered as a potential candidate to repair or build steel reinforced concrete members.

Regarding the effect of NS on rheology, the workability of the mix significantly decreases. Indeed, given the ionic strength of the pore solution and the calcium concentration, the range of electrostatic repulsion is limited and the zeta potential is low, thus altering the rheology of the mix and increasing the water demand. The effect on the slump is so effective that NS particles can be efficiently used as a thickening agent of cement paste whenever a reduced slump is required, such as $3 \mathrm{D}$ printing of structures. Indeed, the shear strength of the cement paste is significantly increased by incorporating NS particles.

On the one hand, the NS particles accelerates the hydration kinetics, thus leading to very high early strength. On the other hand, the NS particles alter the rheology to the point that the strength of the cement paste decreases due to the additional trapped air. The relationship between the Young modulus and the compressive strength of the cement paste is not significantly affected by incorporating NS particles. It must be recalled that all our experiments were performed without plasticizer to ease the understanding of the physical phenomenon and introducing some plasticizer could resolve the issue related to rheology.

Finally, a ternary blend can be formulated so as to turn the improved hydration kinetics into a substantial reduction of $\mathrm{CO}_{2}$ emissions by partially substituting fly ash to the cement without compromising the early strength or the long term strength. Nevertheless, further investigations on durability issues such as shrinkage, permeability and creep are required prior to any structural use of these new materials.

\section{Appendix A. The double layer potential}

Let's compute the energy of two parallel plates $(z=-\delta / 2$ and $z=-\delta / 2)$ at potential $\Psi_{1}, \Psi_{2}$ separated by water. The potential $\Phi$ is related to the density of charges through the Poisson equation:

$$
\Delta \Psi(r)=-\frac{1}{\epsilon_{0} \epsilon_{r}}\left[\sum_{i} q_{i} n_{i}(r)+\rho(r)\right]
$$

where $n_{i}(r)$ is the number concentration of the ion $i, q_{i}$ is the charge of the ion, $\epsilon_{0}=$ $8.854187817 e-12 \mathrm{~A}^{2} \cdot \mathrm{s}^{4} \mathrm{~kg}^{-1} \cdot \mathrm{m}^{-3}$ is the permittivity of vacuum, $\epsilon_{r}$ is the relative permeability of water $(\approx 80)$. The chemical potential of ions $\mu_{i}$ is assumed to be similar to the one of ideal gas if the effect of charge is omitted. As a result, the electrochemical potential of ions $i$ writes:

$$
\mu_{i}=\mu_{i}^{b}+k_{B} T \ln \left(\frac{n_{i}(r)}{n_{i}^{b}}\right)+q_{i} \Psi(r)
$$


where $n_{i}(r)$ is the concentration of ions $i$ and $n_{i}^{b}, \mu_{i}^{b}$ are respectively the concentration and the electrochemical potential of ions in the bulk of the solution where $\Psi(r)=0$. Upon equilibrium, the electrochemical potential of ions is uniform. Consequently, the local ion concentration $n_{i}(r)$ is set according to a Boltzmann distribution:

$$
n_{i}(r)=n_{i}^{b} e^{-\frac{q_{i} \Psi(r)}{k_{B} T}}
$$

where $k_{B}=1.38064852 e-23 \mathrm{JK}^{-1}$ is the Boltzmann constant. As a result, the PoissonBoltzmann equation writes:

$$
\Delta \Psi(r)=-\frac{1}{\epsilon_{0} \epsilon_{r}}\left[\sum_{i} q_{i} n_{i}^{b} e^{-\frac{q_{i} \Psi(r)}{k_{B} T}}+\rho(r)\right]
$$

The potential is assumed to be small $\left(q_{i} \Psi(r)<<k_{B} T\right)$. As a result, the previous equation can be linearised to write the Debye and Hückel equation:

$$
\Delta \Psi(r)=k^{2} \Psi(r)-\frac{1}{\epsilon_{0} \epsilon_{r}} \rho(r)
$$

where $k=\sqrt{2 I /\left(k_{B} T \epsilon_{0} \epsilon_{r}\right)}$ is the inverse of the Debye length and $I=0.5 \sum_{i} q_{i}^{2} n_{i}^{b}$ is the ionic strength.

If the plates are large enough with respect to this length, the potential is only variable in the $z$ direction and the solution to the previous equation is:

$$
\Psi(z)=\frac{\Psi_{1}+\Psi_{2}}{2} \frac{\operatorname{ch}(k z)}{\operatorname{ch}\left(\frac{k \delta}{2}\right)}+\frac{\Psi_{2}-\Psi_{1}}{2} \frac{\operatorname{sh}(k z)}{\operatorname{sh}\left(\frac{k \delta}{2}\right)}
$$

The electric field $E=-\nabla \Psi$ derives from this potential:

$$
E_{z}(z)=-k \frac{\Psi_{1}+\Psi_{2}}{2} \frac{\operatorname{sh}(k z)}{\operatorname{ch}\left(\frac{k \delta}{2}\right)}-k \frac{\Psi_{2}-\Psi_{1}}{2} \frac{\operatorname{ch}(k z)}{\operatorname{sh}\left(\frac{k \delta}{2}\right)}
$$

The electric field in the conducting particles is null and the surface charges $\sigma_{1}, \sigma_{2}$ must balance the jump of the electric field at the surface of the particles:

$$
\begin{aligned}
& \sigma_{1}=\epsilon_{0} \epsilon_{r} E_{z}\left(-\frac{\delta}{2}\right)=\epsilon_{0} \epsilon_{r} k \frac{\Psi_{1}+\Psi_{2}}{2} \frac{\operatorname{sh}\left(\frac{k \delta}{2}\right)}{\operatorname{ch}\left(\frac{k \delta}{2}\right)}-\epsilon_{0} \epsilon_{r} k \frac{\Psi_{2}-\Psi_{1}}{2} \frac{\operatorname{ch}\left(\frac{k \delta}{2}\right)}{\operatorname{sh}\left(\frac{k \delta}{2}\right)} \\
& \sigma_{2}=-\epsilon_{0} \epsilon_{r} E_{z}\left(\frac{\delta}{2}\right)=\epsilon_{0} \epsilon_{r} k \frac{\Psi_{1}+\Psi_{2}}{2} \frac{\operatorname{sh}\left(\frac{k \delta}{2}\right)}{\operatorname{ch}\left(\frac{k \delta}{2}\right)}+\epsilon_{0} \epsilon_{r} k \frac{\Psi_{2}-\Psi_{1}}{2} \frac{\operatorname{ch}\left(\frac{k \delta}{2}\right)}{\operatorname{sh}\left(\frac{k \delta}{2}\right)}
\end{aligned}
$$

Appendix A.0.1. The osmotic pressure between two planar surfaces

Isothermal changes of the electrochemical potentials of ions is related to changes of the pressure $\Pi$ through the Gibbs-Duhem equation:

$$
\sum_{i} N_{i} \mathrm{~d} \mu_{i}=V \mathrm{~d} \Pi
$$

where $N_{i}$ is the number of ions $i$ in the volume $V$.

$$
\sum_{i} n_{i}(r) \mathrm{d} \mu_{i}(r)=\mathrm{d} \Pi
$$

The electrochemical potential (Eq. A.2) can be introduced in the previous equation:

$$
\mathrm{d} \Pi=\sum_{i} n_{i}(r) \mathrm{d}\left(k_{B} T \ln \left(\frac{n_{i}(r)}{n_{i}^{b}}\right)+q_{i} \Psi(r)\right)=k_{B} T \sum_{i} \mathrm{~d} n_{i}(r)+\sum_{i} n_{i}(r) q_{i} \mathrm{~d} \Psi(r)
$$

The Poisson equation is applied to introduce the potential in the second term of the previous equation:

$$
\mathrm{d} \Pi=k_{B} T \sum_{i} \mathrm{~d} n_{i}(r)-\epsilon_{0} \epsilon_{r} \Delta \Psi(r) \mathrm{d} \Psi_{i}(r)
$$

Then, using the expression of the potential in equation A.6. it must be noticed that $\Delta \Psi(r) \frac{\mathrm{d} \Psi(r)}{\mathrm{d} \delta}=$ $\frac{\partial^{2} \Psi}{\partial z^{2}}(z) \frac{\mathrm{d} \Psi(z)}{\mathrm{d} \delta}=\frac{1}{2} \frac{\mathrm{d}\left(\frac{\partial \Psi}{\partial z}\right)^{2}(z)}{\mathrm{d} \delta}:$

$$
\frac{\mathrm{d} \Pi}{\mathrm{d} \delta}=\frac{\mathrm{d}}{\mathrm{d} \delta}\left(k_{B} T \sum_{i} n_{i}(z)-\frac{\epsilon_{0} \epsilon_{r}}{2}\left(\frac{\partial \Psi}{\partial z}\right)^{2}(z)\right)
$$


The pressure is then integrated, the pressure being null if $\delta$ is infinite:

$$
\Pi=k_{B} T \sum_{i}\left(n_{i}(z)-n_{i}^{b}\right)-\frac{\epsilon_{0} \epsilon_{r}}{2}\left(\frac{\partial \Psi}{\partial z}\right)^{2}(z)
$$

Since $q_{i} \Psi(r)<<k_{B} T$, the ion concentration can be approximated by $n_{i}(z)=n_{i}^{b}\left(1-\frac{q_{i} \Psi(z)}{k_{B} T}+\right.$ $\left.\frac{1}{2} \frac{q_{i}^{2}(\Psi(z))^{2}}{\left(k_{B} T\right)^{2}}\right)$. Accounting for the neutrality of the bulk solution leads to the following expression of the pressure:

$$
\Pi=\frac{\epsilon_{0} \epsilon_{r}}{2}\left[k^{2}(\Psi(z))^{2}-\left(\frac{\partial \Psi}{\partial z}\right)^{2}\right]
$$

The expression above can be applied at any point $z$ within $[-\delta / 2 ; \delta / 2]$. Applying it at $z=0$ writes:

$$
\Pi=k^{2} \epsilon_{0} \epsilon_{r}\left[-\frac{1}{2} \frac{\Psi_{1}^{2}+\Psi_{2}^{2}}{\operatorname{sh}^{2}(k \delta)}+\Psi_{1} \Psi_{2} \frac{\operatorname{ch}(k \delta)}{\operatorname{sh}^{2}(k \delta)}\right]
$$

Depending on the the values of potentials and $\delta$, the osmotic pressure can be positive or negative, thus acting as a repulsive or attractive force per surface unit. Consequently, an interaction energy per surface unit $W_{e, p l a n e}$ can be defined so that the pressure can be derived from it [44]:

$$
W_{e, p l a n e}(\delta)=\int_{\delta}^{+\infty} \Pi(\tau) \mathrm{d} \tau=k \epsilon_{0} \epsilon_{r}\left[\frac{1}{2}\left(\Psi_{1}^{2}+\Psi_{2}^{2}\right)\left(1-\frac{\operatorname{ch}(k \delta)}{\operatorname{sh}(k \delta)}\right)+\Psi_{1} \Psi_{2} \frac{1}{\operatorname{sh}(k \delta)}\right]
$$

Consequently, using the Derjaguin approximation [45], the electrostatic force between two colloidal particles of radiuses $R_{1}, R_{2}$ and potential $\Psi_{1}, \Psi_{2}$ separated by a distance $\delta<<R_{1}, R_{2}$ is:

$$
F(\delta)=2 \pi \frac{R_{1} R_{2}}{R_{1}+R_{2}} W_{e, p l a n e}(\delta)
$$

\section{References}

[1] B.-W. Jo, C.-H. Kim, G. ho Tae, J.-B. Park, Characteristics of cement mortar with nano-sio2 particles, Construction and Building Materials 21 (6) (2007) 1351 - 1355. doi:10.1016/j.conbuildmat.2005.12. 020.

URL http://www.sciencedirect.com/science/article/pii/S095006180600136X

[2] Y. Qing, Z. Zenan, K. Deyu, C. Rongshen, Influence of nano-sio2 addition on properties of hardened cement paste as compared with silica fume, Construction and Building Materials 21 (3) (2007) $539-545$, fracture, Acoustic Emission and NDE in Concrete (KIFA-4). doi:10.1016/j.conbuildmat.2005.09.001 URL http://www.sciencedirect.com/science/article/pii/S0950061805002837

[3] A. R. Khaloo, A. G. Vayghan, M. Bolhassani, Mechanical and microstructural properties of cement paste incorporating nano silica particles with various specific surface areas Key Engineering Materials 478 (2011) 19-24. doi:10.4028/www.scientific.net/KEM.478.19

URL http://www.scientific.net/KEM.478.19

[4] H. Biricik, N. Sarier, Comparative study of the characteristics of nano silica - , silica fume - and fly ash - incorporated cement mortars, Materials Research 17 (2014) 570 - 582. doi:10.1590/ S1516-14392014005000054

URL http://dx.doi.org/10.1590/S1516-14392014005000054

[5] H.-S. Lee, H.-K. Cho, X.-Y. Wang, Experimental investigation and theoretical modeling of nanosilica activity in concrete, Journal of Nanomaterials 2014 (2014) 1-10. doi:10.1155/2014/102392.

URL https://www .hindawi.com/journals/jnm/2014/102392/cta/

[6] M. Rupasinghe, R. S. Nicolas, P. Mendis, M. Sofi, T. Ngo, Investigation of strength and hydration characteristics in nano-silica incorporated cement paste, Cement and Concrete Composites 80 (2017) 17 - 30. doi:10.1016/j.cemconcomp.2017.02.011

URL http://www.sciencedirect.com/science/article/pii/S0958946517301634

[7] A. Hanif, P. Parthasarathy, H. Ma, T. Fan, Z. Li, Properties improvement of fly ash cenosphere modified cement pastes using nano silica, Cement and Concrete Composites 81 (2017) $35-48$. doi:10.1016/j. cemconcomp.2017.04.008

URL http://www.sciencedirect.com/science/article/pii/S0958946516305546

[8] A. Said, M. Zeidan, M. Bassuoni, Y. Tian, Properties of concrete incorporating nano-silica, Construction and Building Materials 36 (2012) 838 - 844. doi:10.1016/j.conbuildmat.2012.06.044.

URL http://www.sciencedirect.com/science/article/pii/S0950061812004369

[9] G. Quercia, P. Spiesz, G. Hüsken, H. Brouwers, Scc modification by use of amorphous nano-silica, Cement and Concrete Composites 45 (2014) 69 - 81. doi:10.1016/j.cemconcomp.2013.09.001. URL http://www.sciencedirect.com/science/article/pii/S0958946513001297

[10] G. Quercia, G. Hüsken, H. Brouwers, Water demand of amorphous nano silica and its impact on the workability of cement paste, Cement and Concrete Research 42 (2) (2012) $344-357$. doi:10.1016/j. cemconres.2011.10.008.

URL http://www.sciencedirect.com/science/article/pii/S0008884611002821

[11] B. V. Derjaguin, L. Landau, Theory of the Stability of Strongly Charged Lyophobic Sols and of the Adhesion of Strongly Charged Particles in Solutions of Electrolytes, Acta Phys. Chim. URSS 14 (1941) 633-662. 
[12] E. Verwey, J. Overbeek, K. van Nes, Theory of the Stability of Lyophobic Colloids: The Interaction of Sol Particles Having an Electric Double Layer, Elsevier Publishing Company, 1948.

URL https://books . google.fr/books?id=uEOMnQEACAAJ

[13] J. A. Davis, R. O. James, J. O. Leckie, Surface ionization and complexation at the oxide/water interface: I. computation of electrical double layer properties in simple electrolytes, Journal of Colloid and Interface Science 63 (3) (1978) 480 - 499. doi:10.1016/S0021-9797(78)80009-5

URL http://www.sciencedirect.com/science/article/pii/S0021979778800095

[14] S. K. Milonjić, Determination of surface ionization and complexation constants at colloidal silica/electrolyte interface. Colloids and Surfaces 23 (4) (1987) $301-312$. doi:10.1016/0166-6622(87) 80273-1.

URL http://www.sciencedirect.com/science/article/pii/0166662287802731

[15] H. Viallis-Terrisse, Interaction des Silicate de Calcium Hydratés, principaux constituants de ciment, avec les chlorures d'alcalins. analogie avec les argiles., Ph.D. thesis, Université de Bourgogne (2000).

[16] H. Viallis-Terrisse, A. Nonat, J.-C. Petit, Zeta-potential study of calcium silicate hydrates interacting with alkaline cations, Journal of Colloid and Interface Science 244 (1) (2001) 58 - 65. doi:10.1006/ jcis.2001.7897.

URL http://www.sciencedirect.com/science/article/pii/S002197970197897X

[17] H. Brouwers, R. vanEijk, Alkali concentrations of pore solution in hydrating opc, Cement and Concrete Research 33 (2) (2003) 191 - 196, papers presented at the Fall 2001 Materials Research Society Symposium on Design, Characteristics and Properties of Cementitious Materials. doi:10.1016/S0008-8846(02) 01022-0

URL http://www.sciencedirect.com/science/article/pii/S0008884602010220

[18] European Commission, Reference document on best available techniques for the manufacture of large volume inorganic chemicals - solids and others industry, Tech. Rep. BREF LVIC-S, EC (2007).

URL http://eippcb.jrc.ec.europa.eu/reference/BREF/lvic-s_bref_0907.pdf

[19] Association Technique de l'Industrie des Liants Hydrauliques, Module d'informations environnementales de la production de ciments courants en France, Tech. Rep. version 2, ATILH (june 2011).

[20] T. Lindstad, S. E. Olsen, G. Tranell, T. Faerden, J. Lubetsky, Greenhouse gas emissions from ferroalloy production, in: Infacon XI, 2007, pp. $1-10$.

URL http://www.pyrometallurgy.co.za/InfaconXI/457-Lindstad.pdf

[21] L. Senff, J. A. Labrincha, V. M. Ferreira, D. Hotza, W. L. Repette, Effect of nano-silica on rheology and fresh properties of cement pastes and mortars, Construction and Building Materials 23 (7) (2009) 2487 - 2491. doi:10.1016/j.conbuildmat.2009.02.005

URL http://www.sciencedirect.com/science/article/pii/S0950061809000609

[22] X. Liu, L. Chen, A. Liu, X. Wang, Effect of nano-caco3 on properties of cement paste, Energy Procedia 16, Part B (2012) 991 - 996, 2012 International Conference on Future Energy, Environment, and Materials. doi:10.1016/j.egypro.2012.01.158

URL http://www.sciencedirect.com/science/article/pii/S1876610212001683

[23] AFNOR, Méthodes d'essais des ciments partie 1: détermination des resistances, Tech. Rep. NF EN 196-1, AFNOR (2016).

URL https://www . boutique . afnor .org/norme/nf-en-196-1/methodes-d-essais-des-ciments-partie-1-determination article/866862/fa184622

[24] AFNOR, Essais pour béton durci - partie 2: confection et conservation des éprouvettes pour essais de résistance, Tech. Rep. NF EN 12390-2, AFNOR (2012).

URLhttps://www.boutique.afnor.org/norme/nf-en-12390-2/essais-pour-beton-durci-partie-2-confection-et-cons article/797558/fa155373

[25] F. Lavergne, A. Ben Fraj, I. Bayane, J. Barthélémy, Estimating the mechanical properties of hydrating blended cementitious materials: An investigation based on micromechanics, Cement and Concrete Research $104(2018) 37-60$. doi:10.1016/j. cemconres.2017.10.018 URL http://www.sciencedirect.com/science/article/pii/S0008884617304015

[26] Y. Gu, Q. Ran, W. She, J. Liu, Modifying cement hydration with ns@pce core-shell nanoparticles Advances in Materials Science and Engineering 2017 (2017) 13. doi:10.1155/2017/3823621 URL https://www.hindawi.com/journals/amse/2017/3823621/cta/

[27] E. Berodier, K. Scrivener, Understanding the filler effect on the nucleation and growth of c-s-h, Journal of the American Ceramic Society 97 (12) 3764-3773. arXiv:https://onlinelibrary.wiley.com/doi/ pdf/10.1111/jace.13177, doi:10.1111/jace.13177

URL https://onlinelibrary.wiley.com/doi/abs/10.1111/jace.13177

[28] H. Taylor, Cement Chemistry, Thomas Telford, 1997.

[29] A. Neville, A. Neville, Properties of Concrete, Pearson, 2011.

[30] F. Torabian Isfahani, E. Redaelli, W. Li, Y. Sun, Effects of nanosilica on early age stages of cement hydration, Journal of Nanomaterials 2017 (2017) 9. doi:10.1155/2017/4687484 URL https://www.hindawi.com/journals/jnm/2017/4687484/cta/

[31] I. Pane, W. Hansen, Investigation of blended cement hydration by isothermal calorimetry and thermal analysis Cement and Concrete Research 35 (6) (2005) 1155 - 1164. doi:10.1016/j.cemconres.2004. 10.027 .

URL http://www.sciencedirect.com/science/article/pii/S0008884604004818

[32] R. Day, Reactions between methanol and portland cement paste, Cement and Concrete Research 11 (3) (1981) $341-349$. doi:10.1016/0008-8846(81) 90106-X.

URL http://www.sciencedirect.com/science/article/pii/000888468190106X

[33] J. J. Beaudoin, Validity of using methanol for studying the microstructure of cement paste, Materials and Structures 20 (1) (1987) 27-31. doi:10.1007/BF02472723

URL https://doi.org/10.1007/BF02472723

[34] B. Lothenbach, P. Durdziński, K. De Weerdt, Thermogravimetric analysis, in: K. Scrivener, R. Snellings, B. Lothenbach (Eds.), A Practical Guide to Microstructural Analysis of Cementitious Materials, CRC Press, 2016, pp. 177-211. doi:10.1201/b19074-6

[35] R. Walker, S. Pavía, Physical properties and reactivity of pozzolans, and their influence on the prop- 
erties of lime-pozzolan pastes, Materials and Structures 44 (6) (2011) 1139-1150. doi:10.1617/ s11527-010-9689-2.

URL https://doi.org/10.1617/s11527-010-9689-2

[36] F. de Larrard, Structures granulaires et formulation des bétons - Concrete Mixture - Proportionning - A scientific approach, Modern technology Series, E \& FN SPON, Londres, 1999.

[37] M. Yang, C. Neubauer, H. Jennings, Interparticle potential and sedimentation behavior of cement suspensions: Review and results from paste, Advanced Cement Based Materials 5 (1) (1997) $1-7$. doi:10.1016/S1065-7355(97)90009-2

URL http://www.sciencedirect.com/science/article/pii/S1065735597900092

[38] Y. Zhang, Study on Microstructure and Rheological Properties of Cement-Chemical Admixtures-Water Dispersion System at Early Stage, Springer Singapore, Singapore, 2018, pp. 1-36. doi:10.1007/ 978-981-10-4570-7_1.

URL https://doi .org/10.1007/978-981-10-4570-7_1

[39] D. Lowke, C. Gehlen, The zeta potential of cement and additions in cementitious suspensions with high solid fraction, Cement and Concrete Research 95 (2017) 195 - 204. doi:10.1016/j.cemconres.2017. 02.016 . URL http://www.sciencedirect.com/science/article/pii/S0008884616304975

[40] J. Plank, C. Schroefl, M. Gruber, M. Lesti, R. Sieber, Effectiveness of polycarboxylate superplasticizers in ultra-high strength concrete: The importance of pce compatibility with silica fume, Journal of Advanced Concrete Technology 7 (1) (2009) 5-12. doi:10.3151/jact.7.5

[41] E. Nägele, The zeta-potential of cement, Cement and Concrete Research 15 (3) (1985) 453 - 462. doi: 10.1016/0008-8846(85)90118-8.

URL http://www.sciencedirect.com/science/article/pii/0008884685901188

[42] H. Hamaker, The London - van der Waals attraction between spherical particles, Physica 4 (10) (1937) 1058 - 1072. doi:10.1016/S0031-8914(37)80203-7.

URL http://www.sciencedirect.com/science/article/pii/S0031891437802037

[43] R. J. Flatt, Dispersion forces in cement suspensions, Cement and Concrete Research 34 (3) (2004) 399 408. doi:10.1016/j.cemconres.2003.08.019

URL http://www.sciencedirect.com/science/article/pii/S0008884603002989

[44] R. Hogg, T. W. Healy, D. W. Fuerstenau, Mutual coagulation of colloidal dispersions, Trans. Faraday Soc. 62 (1966) 1638-1651. doi:10.1039/TF9666201638

URL http://dx.doi.org/10.1039/TF9666201638

[45] B. Derjaguin, Untersuchungen über die reibung und adhäsion, iv, Kolloid-Zeitschrift 69 (2) (1934) 155164. doi:10.1007/BF01433225 URL https://doi.org/10.1007/BF01433225

[46] Gouy, M., Sur la constitution de la charge électrique à la surface d'un électrolyte, J. Phys. Theor. Appl. 9 (1) (1910) 457-468. doi:10.1051/jphystap:019100090045700. URL https://doi.org/10.1051/jphystap:019100090045700

[47] D. L. Chapman, Li. a contribution to the theory of electrocapillarity, The London, Edinburgh, and Dublin Philosophical Magazine and Journal of Science 25 (148) (1913) 475-481. arXiv:https://doi.org/10. 1080/14786440408634187, doi:10.1080/14786440408634187 URL https://doi .org/10.1080/14786440408634187

[48] A. Truesdell, B. Jones, G. S. (U.S.), WATEQ: A Computer Program for Calculating Chemical Equilibria of Natural Waters, U.S. Department of the Interior, Geological Survey, 1973.

[49] J. W. Ball, D. K. Nordstrom, G. S. (U.S.), User's manual for WATEQ4F, with revised thermodynamic data base and test cases for calculating speciation of major, trace and redox elements in natural waters, U.S. Department of the Interior, Geological Survey, 2001.

[50] J. Kielland, Individual activity coefficients of ions in aqueous solutions, Journal of the American Chemical Society 59 (9) (1937) 1675-1678. arXiv:http://dx.doi.org/10.1021/ja01288a032, doi: 10.1021/ja01288a032.

URL http://dx.doi .org/10.1021/ja01288a032

[51] H. M. Jennings, Refinements to colloid model of c-s-h in cement: Cm-ii, Cement and Concrete Research 38 (3) (2008) 275 - 289. doi:10.1016/j.cemconres.2007.10.006.

URL http://www.sciencedirect.com/science/article/pii/S0008884607002761

[52] B. Lothenbach, T. Matschei, G. Möschner, F. P. Glasser, Thermodynamic modelling of the effect of temperature on the hydration and porosity of portland cement, Cement and Concrete Research 38 (1) (2008) 1 - 18. doi:10.1016/j.cemconres.2007.08.017

URL http://www.sciencedirect.com/science/article/pii/S0008884607001998

[53] A. V. Bandura, S. N. Lvov, The ionization constant of water over wide ranges of temperature and density, Journal of Physical and Chemical Reference Data 35 (1) (2006) 15-30. arXiv:https://doi. org/10.1063/1.1928231, doi:10.1063/1.1928231.

URL https://doi .org/10.1063/1.1928231

[54] J. J. Thomas, D. Rothstein, H. M. Jennings, B. J. Christensen, Effect of hydration temperature on the solubility behavior of ca-, s-, al-, and si-bearing solid phases in portland cement pastes, Cement and Concrete Research 33 (12) (2003) 2037 - 2047. doi:10.1016/S0008-8846(03) 00224-2.

URL http://www.sciencedirect.com/science/article/pii/S0008884603002242

[55] A. M. Couture, K. J. Laidler, The partial molal volumes of ions in aqueous solution: I. dependence on charge and radius Canadian Journal of Chemistry 34 (9) (1956) 1209-1216. arXiv:https://doi.org/ 10.1139/v56-158, doi:10.1139/v56-158 URL https://doi.org/10.1139/v56-158

[56] I. Lambert, H. L. Clever, Alkaline earth hydroxides in water and aqueous solutions, Solubility Data Series 52 (1992) 1-388.

[57] H. C. Helgeson, D. H. Kirkham, G. C. Flowers, Theoretical prediction of the thermodynamic behavior of aqueous electrolytes by high pressures and temperatures; iv, calculation of activity coefficients, osmotic coefficients, and apparent molal and standard and relative partial molal properties to 600 degrees c and 5kb, American Journal of Science 281 (10) (1981) 1249-1516. arXiv:http://www.ajsonline.org/ 
content/281/10/1249.full.pdf+html, doi:10.2475/ajs.281.10.1249

URL http://www . ajsonline.org/content/281/10/1249. short

[58] C. Appelo, D. Parkhurst, V. Post, Equations for calculating hydrogeochemical reactions of minerals and gases such as co2 at high pressures and temperatures, Geochimica et Cosmochimica Acta 125 (2014) 49 -67. doi:10.1016/j.gca.2013.10.003

URL http://www.sciencedirect.com/science/article/pii/S001670371300553X

[59] N. Roussel, P. Coussot, "fifty-cent rheometer" for yield stress measurements: From slump to spreading flow, Journal of Rheology 49 (3) (2005) 705-718. arXiv:https://doi.org/10.1122/1.1879041, doi: 10.1122/1.1879041

URL https://doi .org/10.1122/1.1879041

[60] N. Roussel, A theoretical frame to study stability of fresh concrete, Materials and Structures 39 (1) (2006) 81-91. doi:10.1617/s11527-005-9036-1.

URL https://doi.org/10.1617/s11527-005-9036-1

[61] T. T. Le, S. A. Austin, S. Lim, R. A. Buswell, A. G. F. Gibb, T. Thorpe, Mix design and fresh properties for high-performance printing concrete, Materials and Structures 45 (8) (2012) 1221-1232. doi:10.1617/ s11527-012-9828-z

URL https://doi.org/10.1617/s11527-012-9828-z

[62] K. Snyder, X. Feng, B. Keen, T. Mason, Estimating the electrical conductivity of cement paste pore solutions from oh-, k+ and na+ concentrations, Cement and Concrete Research 33 (6) (2003) $793-798$. doi:10.1016/S0008-8846(02)01068-2

URL http://www.sciencedirect.com/science/article/pii/S0008884602010682

[63] M. A. Brown, Z. Abbas, A. Kleibert, R. G. Green, A. Goel, S. May, T. M. Squires, Determination of surface potential and electrical double-layer structure at the aqueous electrolyte-nanoparticle interface, Phys. Rev. X 6 (2016) 011007. doi:10.1103/PhysRevX.6.011007

URL https://link.aps.org/doi/10.1103/PhysRevX.6.011007

[64] A. Ioannidou, Precipitation, gelation and mechanical properties of Calcium-Silicate-Hydrate gels, Ph.D. thesis, ETH Zurich (2014).

[65] H. Uchikawa, S. Hanehara, D. Sawaki, The role of steric repulsive force in the dispersion of cement particles in fresh paste prepared with organic admixture, Cement and Concrete Research 27 (1) (1997) 37 - 50. doi:10.1016/S0008-8846(96)00207-4.

URL http://www.sciencedirect.com/science/article/pii/S0008884696002074

[66] T. Sowoidnich, T. Rachowski, C. Rößler, A. Völkel, H.-M. Ludwig, Calcium complexation and cluster formation as principal modes of action of polymers used as superplasticizer in cement systems, Cement and Concrete Research 73 (Supplement C) (2015) 42 - 50. doi:10.1016/j.cemconres.2015.01.016 URL http://www.sciencedirect.com/science/article/pii/S0008884615000290

[67] AFNOR, Méthodes d'essais des ciments - partie 9 : Chaleur d'hydratation - méthode semi-adiabatique, Tech. Rep. NF EN 196-9, AFNOR (2010).

[68] D. D. Wagman, W. H. Evans, V. B. Parker, R. H. Schumm, I. Halow, S. M. Bailey, K. L. Churney, R. L. Nuttall, The nbs tables of chemical thermodynamic properties. selected values for inorganic and $\mathrm{c} 1$ and c2 organic substances in si units, Journal of Physical and Chemical Reference Data 11 (1982) 1-407, supplement No. 2.

URL http://www.nist.gov/data/PDFfiles/jpcrdS2Vol11.pdf

[69] R. A. Robie, B. S. Hemingway, J. R. Fisher, Thermodynamic properties of minerals and related substances at $298.15 \mathrm{k}$ and 1 bar $\left(10^{5}\right.$ pascals $)$ pressure and at higher temperatures, USGS Numbered Series 2131 (1995) 1-461.

[70] T. Matschei, Thermodynamics of cement hydration, Ph.D. thesis, University of Aberdeen (2007). 